\title{
Why England? Demographic factors, structural change and physical capital accumulation during the Industrial Revolution
}

\author{
Nico Voigtländer • Hans-Joachim Voth
}

(C) Springer Science+Business Media, LLC 2006

\begin{abstract}
Why did England industrialize first? And why was Europe ahead of the rest of the world? Unified growth theory in the tradition of Galor and Weil (2000, American Economic Review, 89, 806-828) and Galor and Moav (2002, Quartely Journal of Economics, 177(4), 1133-1191) captures the key features of the transition from stagnation to growth over time. Yet we know remarkably little about why industrialization occurred much earlier in some parts of the world than in others. To answer this question, we present a probabilistic two-sector model where the initial escape from Malthusian constraints depends on the demographic regime, capital deepening and the use of more differentiated capital equipment. Weather-induced shocks to agricultural productivity cause changes in prices and quantities, and affect wages. In a standard model with capital externalities, these fluctuations interact with the demographic regime and affect the speed of growth. Our model is calibrated to match the main characteristics of the English economy in 1700 and the observed transition until 1850. We capture one of the key features of the British Industrial Revolution emphasized by economic historians - slow growth of output and productivity. Fertility limitation is responsible for higher per capita incomes, and these in turn increase industrialization probabilities. The paper also explores the availability of nutrition for poorer segments of society. We examine the influence of redistributive institutions such as the Old Poor Law, and find they were not decisive in fostering industrialization. Simulations using parameter values for other countries show that Britain's early escape was only partly due to chance. France could have moved out of agriculture and into manufacturing faster than Britain, but the probability was less than $25 \%$. Contrary to recent claims in the literature, 18th century China had only a minimal chance to escape from Malthusian constraints.
\end{abstract}

\footnotetext{
N. Voigtländer

Economics Department, Universitat Pompeu Fabra, c/Ramon Trias Fargas 25-27, E-08005 Barcelona, Spain

H.-J. Voth $(\bowtie)$

ICREA and Economics Department, Universitat Pompeu Fabra, c/Ramon Trias Fargas 25-27, E-08005 Barcelona, Spain
} 
Keywords Industrial Revolution - Unified growth theory - Endogenous growth .

Transition · Calibration · British economic growth before 1850

JEL Classifications $\quad \mathrm{E} 27 \cdot \mathrm{N} 13 \cdot \mathrm{N} 33 \cdot \mathrm{O} 14 \cdot \mathrm{O} 41$

\section{Introduction}

Britain was the first country to break free from Malthusian constraints, with population size and living standards starting to grow in tandem after 1750 (Crafts, 1985; Wrigley, 1983). In many parts of the world, however, growth rates of per capita income took a long time to accelerate. Eventually, more and more countries industrialized, first in Europe and North America, and from the 20th century onwards in other areas of the globe. The relative size of economies, the onset of the demographic transition, and living standards of citizens are still profoundly influenced by the timing of Industrial Revolutions around the globe (Galor \& Mountford, 2003) - with dramatic consequences for the economic and political history of the world that are still felt today world.

Why did some countries industrialize so much earlier than others? Unified growth theory (Galor \& Weil, 2000; Galor \& Moav, 2002; Hansen \& Prescott, 2002; Jones, 2001) offers a consistent explanation for the transition from century-long Malthusian stagnation to rapid growth. What is missing is a better understanding of why some countries overcame stagnation at radically different points in time. The question is almost as old as industrialization itself. Economic historians have stressed a long list of factors, ranging from the property rights regime to the land tenure system, that might have favored Britain (Landes, 1999). Galor (2005) argues that geographical factors and historical accident interacted to delay or accelerate the timing of the "Great Escape," and that "variations in institutional, demographic, and cultural factors, trade patterns, colonial status, and public policy" may have played a role. This paper aims to provide a systematic answer to the questions "Why England?" and "Why Europe?" In doing so, it offers clear quantitative evidence on the role of starting conditions and the nature of constraints that delayed industrialization for centuries in many parts of the world.

In our model, chance can play an important role. Industrialization is treated as the result of a probabilistic process. During the late medieval and early modern period, brief expansions - "efflorescences" - occurred in many countries (Braudel, 1973; Goldstone, 2002). Yet most of these growth episodes sooner or later ground to a halt. Some advanced economies (such as the Italian Republics) went into decline, while countries like the Netherlands stagnated at high income levels. This is why economic historians have often been sceptical of industrialization theories where the final outcome is pre-determined (Clark, 2003a; Mokyr \& Voth, 2008). What explains these starts and stops? And could other countries have succeeded before Britain? Crafts (1977) argued that accidental factors, and not systematic advantages, may have been crucial - that France, for example, could have easily industrialized first had it not been for a number of random factors. To examine the determinants of early economic development, this paper develops a simple stochastic model of the first Industrial Revolution - the transition from the Malthusian to the post-Malthusian regime, in the terminology of unified growth theory. In the spirit of Stokey (2001), our model is then calibrated with eighteenth-century English data. We find that chance played a 
role in the timing and speed of Britain's initial surge - it's actual performance was in the upper half of the expected range of outcomes in our model. By altering the parameters of the calibrated model, we derive probabilities of the escape in other parts of the world. France could have experienced substantial growth, based on our model, but the manufacturing employment share in 1850 is lower than in Britain in most of our simulations.

As emphasized by Galor and Moav (2004), physical capital accumulation is crucial for the first transition. This is reflected in our model, which emphasizes TFP advances as a result of growing capital inputs. The key factors influencing industrialization probabilities in our model are starting incomes, the nature of shocks, inequality, and the demographic regime. In our calibrations, we find that England's (and Europe's) chances of sustained growth were greater principally because the demographic regime propped up initial incomes. Redistribution plays only a small role. Galor and Moav (2004) argue that inequality should be beneficial for industrialization in its initial stages, when physical capital is crucial; during the second transition to self-sustaining growth, human capital becomes a key input, and inequality is harmful. Zweimüller (2000) shows how, in an endogenous growth model, redistribution can be growthenhancing, while Matsuyama (2002) demonstrates how development depends on the exact shape of the income distribution. We add another dimension emphasized by Fogel (1994). As many as $20 \%$ of the population in 18th century France possibly did not receive enough food to work for more than a few hours a day. Also, when inequality was too great prior to the Industrial Revolution, crisis mortality could be high. This undermines growth by lowering the marginal return to capital, and the pace of accumulation. If this effect is larger than the rise in the capital/labor and land/labor ratios due to falling population, productivity growth suffers. We conclude that inequality may only be beneficial via the savings channel if the population is sufficiently well-fed to avoid famines and chronic undernutrition.

Our work is related to three bodies of literature. Economic historians have sometimes been sceptical of endogenous growth models. ${ }^{1}$ Crafts (1995) rejected them partly because they had little to say about the different speeds of industrialization in England and France. He also argued that detailed accounts of technological historians did not square with the predictions of endogeneous growth models. Unified growth theory has made considerable progress in bridging the gap between theory and historical facts. We therefore take the models by Galor and Moav (2002), Galor and Weil (2000), Jones (2001), Kögel and Prskawetz (2001) and Cervellati and Sunde (2005) as our starting point. Our model focuses on what Galor et al. call the first of two crucial transitions - the one from Malthusian to a post-Malthusian world, when population pressure no longer determines wages (but before human capital becomes crucial). In the vein of these models, demographic feedback and physical capital accumulation are important for the initial escape from stagnation. While papers in the Galor-Weil tradition focus on fertility limitation after the first transition, we emphasize the importance of fertility behavior for starting conditions in Europe (as in the work of Wrigley (1988), inter alia).

A second set of related papers emphasizes technology adoption. Murphy, Shleifer and Vishny (1989a,b) argue that bigger markets and moderate inequality facilitate the adoption of new technologies when fixed costs are substantial. The technological

1 Voth (2003) concluded that "the Industrial Revolution in most growth models shares few similarities with the economic events unfolding in England in the 18th century." 
history of the First Industrial Revolution only offers qualified support for the importance of fixed costs and indivisibilities. Instead, we employ an externality to capital use that is based on the findings of technological historians (Mokyr, 1990). As in Kögel and Prskawetz (2001), we emphasize the interactions between agricultural productivity and industrial growth - an approach that goes back in economic history to Gilboy (1932). Acemoglu and Zilibotti (1997) observe that volatility in poor economies is high. New technologies represent high risk, high return investment. Because of indivisibilities, only richer and larger countries undertake them. A run of "good years" increases the probability of switching to high-productivity projects. In our model, stochastic income fluctuations and starting per capita income play a role because they increase the scope for the capital externality to work.

The third body of literature uses calibrations and simulation methods to shed new light on the industrialization process. Stokey (2001) was amongst the first to employ calibrations for the Industrial Revolution. She concludes that foreign trade and technological change in manufacturing were equally important for growth, but that improvements in energy production mattered less. Crafts and Harley (2000) examine the importance of broad-based technological change in a CGE model, and conclude that slow, sector-specific improvements in TFP are compatible with the observed pattern of trade. Lagerlöf (2003) uses a probabilistic model where mortality fluctuations - epidemics - eventually lead to a transition to self-sustaining growth. Lagerlöf (2006) simulates the Galor-Weil model, and finds that it can replicate most of the important features in the transition from stagnation to growth. Our approach differs from the Stokey approach in that it uses a more explicit model of productivity change. We combine the calibration exercise with the probabilistic models in the spirit of Lagerlöf (2003).

The paper proceeds as follows. Section 2 discusses the historical context and motivation for the paper. It briefly highlights where existing unified growth models are in conflict with the historical record, and sets out the basic elements of our story. Section 3 presents the model, explaining the role of demographic factors and the productivity benefits of differentiated capital inputs. In the next part, we calibrate the model and derive comparative industrialization probabilities for Britain, France, and China. Section 5 concludes.

\section{Historical background and motivation}

We focus on three features of the First Industrial Revolution - the slow, gradual nature of productivity growth and structural change, the role of inequality, and the nature of technological advances. Research in economic history over the last three decades has emphasized the slow and gradual nature of economic and structural change after 1750. Where once scholars argued for a few decades during which the transition to rapid growth occurred, a much more gradualist orthodoxy has taken hold (Crafts \& Harley, 1992; Antras \& Voth 2003). As Table 1 shows, total factor productivity growth rates were barely higher after 1750 than before. What is remarkable about the period after 1750 in Britain is not output growth or TFP performance as such, but the fact that accelerated population growth coincided with stagnant or slowly growing wages and output per head (Mokyr, 1999) - which makes the term "post-Malthusian" (Galor, 2005) particularly apt. During the period, and in line with 
Table 1 Output and productivity growth during the industrial revolution

\begin{tabular}{lllll}
\hline (percent & Feinstein & $\begin{array}{l}\text { Crafts } \\
\text { per annum) }\end{array}$ & $\begin{array}{l}\text { Crafts } \\
\text { and Harley } \\
(1981)\end{array}$ & $\begin{array}{l}\text { Antras } \\
\text { and Voth } \\
(1985)\end{array}$ \\
\hline
\end{tabular}

\begin{tabular}{lllll}
\hline Output & & & & \\
$1760-1800$ & 1.1 & 1 & 1 & \\
$1801-1831$ & 2.7 & 2 & 1.9 & \\
$1831-60$ & 2.5 & 2.5 & 2.5 & \\
Productivity (TFP) & & & & \\
$1760-1800$ & 0.2 & 0.2 & 0.1 & 0.27 \\
$1801-1831$ & 1.3 & 0.7 & 0.35 & 0.54 \\
$1831-1860$ & 0.8 & 1 & 0.8 & 0.33 \\
\hline
\end{tabular}

unified growth theory, investment rates increased from about 7\% of GDP in 1760 to $14 \%$ in 1840 (Crafts, 1985).

One implication of the gradualist school of thought is that per capita living standards in Britain must have been quite high by 1750 already. This underlines the importance of starting conditions. One major factor was the nature of its demographic regime. As Wrigley and Schofield (1981) have argued, social and cultural norms limited fertility in early modern England in a way that few other societies did. This led to higher per capita incomes. England practiced an extreme form of the 'European marriage pattern' - West of a line from St. Petersburg to Triest, age at first marriage for women was determined by socioeconomic conditions, not age at first menarche (Hajnal, 1965). This stabilized per capita living standards and avoided the waste of resources and human lives resulting from Malthus' 'positive' check, when population declines through widespread starvation. Within the European context, England was characterized by a low-pressure demographic regime - negative shocks to income were mainly absorbed by falls in fertility rather than increases in mortality (Wrigley \& Schofield, 1981; Wrigley, Davies, Oeppen, \& Schofield, 1997). Both the higher level of per capita income produced by this demographic regime, and the way in which it was achieved, play a crucial role in our model.

Second, Britain was a highly unequal society in the 17 th and 18 th century (Lindert \& Williamson, 1982; Lindert, 2000). Nonetheless, average British standards of consumption were relatively high compared to French ones, with a markedly higher minimum level of consumption. Fogel (1994) estimated that as a result of higher inequality and lower per capita output, the bottom $20-30 \%$ of the French population did not receive enough food to perform more than a few hours of work. This was partly a result of higher productivity overall - Fogel calculates that the British consumed some $17 \%$ more calories than their French counterparts. Yet the crucial factor may have been support for the poorer parts of society. The Old Poor Law was an unusually generous form of redistribution. At its peak, transfers amounted to $2.5 \%$ of British GDP, and more than $11 \%$ of the population received some form of relief. This may also have had indirect effects for the wages of those who were not recipients, by reducing competition in the labor market and raising the aggregate wage bill (Boyer, 1990). Mokyr (2002) calculates that at its peak the system may have boosted average incomes of the bottom $40 \%$ of society by $14-25 \%$. This ensured that in England, most individuals were sufficiently well-fed to work. It may have also stabilized consumer demand for industrial products. Even during the 1790s, when food prices were high, up to $30 \%$ 
of working class budgets continued to be spent on non-food items (with $6 \%$ going on clothing). With most of the goods produced by the nascent modern sector having high income elasticities of demand (in excess of 2.3), even modest gains in real wages in the later stages of the Industrial Revolution could translate into rapidly growing purchases of manufacturing goods. Finally, because of the large absolute value of the own-price elasticity of non-food spending (of -1.8 amongst the English poor), productivity increases and subsequent price reductions facilitated the growth of the modern sector (Horrell, 1996).

The third element in our story emphasizes the relative importance of innovation versus inventions. Traditionally, economic historians in the tradition of North and Thomas (1973) have emphasized the importance of property rights, especially the patent system. In this view, as the security of property rights improved after the Glorious Revolution in 1688, more inventive activity took place. Technological change accelerated. The problem with this interpretation is that intellectual property rights were poorly protected before the 19th century in England, that few inventors received substantial material rewards, that the role of traditional ("feudal") forms of reward like grants from Parliament dominated benefits from patents, and that non-monetary incentives and chance seem to have played an extraordinarily large part in many of the key breakthroughs. Most of the technologies that made Britain great in 1850 were already known a century before. As Mokyr (1990) has emphasized, the crucial breakthroughs did not take the shape of blueprints or ideas. Instead, a stream of microinventions gave the First Industrial Nation its edge:

"In Britain, [...] the private sector on its own generated the technological breakthroughs and, more importantly, adapted and improved these breakthroughs through a continuous stream of small, anonymous microinventions which cumulatively accounted for the gains in productivity." (Mokyr, 1990)

New ways of adapting and making useful existing technologies were crucial. The Watt steam engine was but a variation of the Newcomen design. Many productivity advances were embodied in better pieces of capital equipment (Mokyr, 1990). What made these advances possible was not a small group of heroic inventors but a small labor aristocracy of highly skilled craftsmen, perhaps no more than $5 \%$ of the workforce overall (Mokyr \& Voth, 2008). These glass-cutters, instrument makers, and specialists in fine mechanics were crucial in turning ideas into working prototypes, or existing machines into reliable capital equipment.

Industrialization occurs in our model in the following way: Incomes fluctuate around their long-run trend, pinned down by the demographic regime in the preindustrial era. Technology improves but slowly through the use of capital itself - the more manufacturing activity there is, the more scope there is for improving and refining existing designs. The higher pre-industrial incomes, the greater the chance that a positive, persistent shock leads to a large increase in manufacturing output. The higher manufacturing output, the more capital-intensive production overall becomes - and the greater the scope for an acceleration of productivity growth because of growing differentiation of capital inputs. This setup resolves the apparent incompatibility of endogenous growth models with the history of technology which was emphasized by Crafts (1995). One of the key criticisms of long-run growth models by economic historians has been that they often imply important and large scale effects - and that countries with bigger markets should have industrialized first (Crafts, 1995). Yet the richest countries in early modern Europe were typically small, as was Britain for 
most of the period before 1750 . We deliberately avoid these pitfalls by offering a mechanism for industrialization that does not presume that bigger countries have an automatic advantage. ${ }^{2}$

Population grows in response to higher wages; positive shocks to income add to demographic pressures, but also increase the scope for the capital externality to work. Crucially, because of fertility limitation, Europe's birth rates never outpace the rate of capital accumulation. We argue that England in particular (and Europe in general) had a higher chance to undergo a transition because of the high initial starting incomes and a favorable demographic regime.

For our argument to hold, England had to be ahead of the rest of Europe - and Europe markedly ahead of the rest of the world - in terms of per capita income. This is not accepted with unanimity. Pomeranz (2000) argues that, in the Yangtze region in China, living standards were broadly similar with the most advanced regions in Europe, and that the "great divergence" between Asia and Europe was a result of industrialization. Broadberry and Gupta (2005a) have recently shown that Pomeranz's claims, even for the Yangtze area, are probably exaggerated. Allen (2005a) finds that because of low rice and grain prices, the standard of living in Asia and Europe was broadly similar. However, money wages were markedly lower, and the relative price of manufacturing goods much higher. This is compatible with our interpretation, since it hinges on the purchasing power of income not dedicated to food.

\section{The model}

This section sets out the basic setup of our model. The economy is composed of infinitely lived, identical households whose members work, consume, invest, and procreate. Households choose consumption and saving to maximize their dynastic utility, subject to an intertemporal budget constraint. We consider a representative household of size $N$. In the following, we will refer to $N$ as population and to household members as consumers or individuals. Current family members expect $N$ to grow at the rate $\gamma_{N}(\cdot)$ because of the net influences of fertility and mortality, depending on consumption. In every period the economy produces two types of consumption goods: food and manufacturing products - as well as investment goods in the form of capital varieties. Output is produced using land, labor, and the accumulated stock of capital varieties. Consumers' preferences are non-homothetic: Representing Engel's law, the share of manufacturing expenditures grows with income. Below, we describe each of these elements of our model in turn.

\subsection{Consumers}

Each household member supplies one unit of labor in every period. Families use their income for investment, and to consume an agricultural good $\left(c_{A}\right)$ and a manufactured good $\left(c_{M}\right)$. Households maximize their expected life-time utility in a two-stage

2 Unified growth theory models in the spirit of Galor-Weil do not predict that bigger countries should industrialize first. Rather, their unit of observation is the world, and they assume that the partial derivative of technological change with respect to population size is positive. At this level of aggregation, economic historians cannot disagree. The difficulty appears to be that for a model that captures cross-sectional differences, factors other than size must be important, and it is these factors that we try to capture. 
decision. In an intertemporal optimization problem, they decide upon consumption expenditure per household member in a given period $t, e_{t}$. In the second stage, the intra-temporal optimization, each individual takes $e_{t}$ as given and maximizes instantaneous utility. We consider the second stage first. The corresponding budget constraint is $c_{A, t}+p_{M, t} c_{M, t} \leq e_{t}$, where $p_{M, t}$ is the price of a manufactured good. The agricultural good serves as the numeraire. Before they begin to demand manufactured goods, individuals need to consume a minimum quantity of food, $\underline{c}$. Preferences take the Stone-Geary form and imply the composite consumption index:

$$
u\left(c_{A}, c_{M}\right)=\left(c_{A}-\underline{c}\right)^{\alpha} c_{M}^{1-\alpha}
$$

Given $e_{t}$, consumers maximize (1) subject to the budget constraint. This yields the following equation for the expenditure share on agricultural products:

$$
\frac{c_{A, t}}{e_{t}}=\alpha+(1-\alpha)\left(\frac{\underline{c}}{e_{t}}\right)
$$

In a poor economy, where income is just enough to ensure subsistence consumption $\underline{c}$, all expenditure goes to food. As people become richer and $e_{t}$ grows, the share of spending on food falls, in line with Engel's law. For very high levels of expenditure, $\underline{c} / e_{t}$ converges to zero and the agricultural expenditure share converges to $\alpha$, which can thus be considered the food expenditure share in a rich economy.

We now turn to intertemporal optimization. First, we derive the indirect utility of consumers from (1) and (2):

$$
\widetilde{u}\left(p_{M, t}, e_{t}\right)=\left(\frac{1}{p_{M, t}}\right)^{1-\alpha} \alpha^{\alpha}(1-\alpha)^{1-\alpha}\left(e_{t}-\underline{c}\right)
$$

We use this result to set up the intertemporal optimization problem. The representative household maximizes expected dynastic utility subject to the intertemporal budget constraint:

$$
\begin{gathered}
\max _{\left\{k_{t+1}\right\}_{t=0}^{\infty}} E_{0} \sum_{t=0}^{\infty} \beta^{t} \frac{\left[\widetilde{u}\left(p_{M, t}, e_{t}\right)\right]^{1-\psi}-1}{1-\psi} N_{t} \\
\text { s.t. } \quad\left(1+\gamma_{N, t}\right) k_{t+1}=(1-\delta) k_{t}+\frac{1}{p_{K, t}}\left(y_{t}-e_{t}\right) \\
y_{t}=w_{t}+r_{L, t} l+R_{K, t} p_{K, t} k_{t}
\end{gathered}
$$

where $y_{t}, e_{t}, k_{t}$, and $l$ are per-capita income, consumption expenditure, capital, and land, respectively, and $p_{K, t}$ is the price of capital. ${ }^{3}$ Factor returns are the gross capital interest rate $R_{K}$, wage $w$, and the land rental rate $r_{L}$. Capital depreciates at rate $\delta ; \beta \in(0,1)$ is the households' discount rate, and $1 / \psi$ gives the (constant) elasticity of intertemporal substitution, where $\psi \geq 1$. Since families take care of the welfare and resources of their prospective descendants, individual instantaneous utility $\left(\widetilde{u}(\cdot)^{1-\psi}-1\right) /(1-\psi)$ is multiplied by household members $N$. Households take population growth $\gamma_{N, t}$ as given when optimizing. Together with the budget constraint, (4) yields the Euler equation

\footnotetext{
3 In our model capital is the collection of varieties (machines). Thus, total capital $K=k N$ is equal to the integral over all capital varieties used in the economy. We provide a formal description of the capital stock below.
} 


$$
\left(\frac{1}{e_{t}-\underline{c}}\right)^{\psi}=\beta E_{t}\left[\left(\frac{p_{K, t+1}}{p_{K, t}}\right)\left(\frac{p_{M, t+1}}{p_{M, t}}\right)^{(1-\alpha)(\psi-1)}\left(\frac{1}{e_{t+1}-\underline{c}}\right)^{\psi}\left(1+R_{K, t+1}-\delta\right)\right]
$$

The Euler equation is the standard one, except for the two price terms on the righthand side. If the price of manufactured goods increases, consumption in the next period will be more expensive. If the elasticity of intertemporal substitution is low (i.e., $\psi>1$ ), the income effect will outweigh the substitution effect, and consumption $e_{t}$ will be lower. If the price of capital $p_{\mathrm{K}}$ is expected to increase, investment is shifted from the future to the present, also lowering today's consumption. We use policy function iteration to solve the Euler equation, as described in Appendix A.6.

\subsection{Production}

Firms produce both capital and final goods. The latter are either agricultural or manufactured, are homogenous, and are produced under perfect competition. Capital is non-homogenous. It comes in many varieties that are produced monopolistically subject to increasing returns. The efficiency of production depends on the number of capital goods varieties. Free entry in the capital-goods producing sector ensures that, in equilibrium, there are no profits.

\subsubsection{Final goods}

Final sector firms use labor $N$, land $L$, and capital in the form of varieties $j \in[0, J]$ to produce their output. The agricultural production function is

$$
Y_{A}=A_{A}\left[\int_{0}^{J} v_{A}(j)^{\frac{1}{1+\epsilon}} \mathrm{d} j\right]^{\phi(1+\epsilon)} N_{A}^{\mu} L^{1-\phi-\mu}
$$

where $A_{A}$ is a productivity parameter in agriculture and $v_{A}(j)$ is the amount of capital variety $j$ used for agricultural production in a representative final sector firm. Productivity fluctuates over time: $A_{A, t}=z_{t} \underline{A}_{A, t}$, where the component $z_{t}$ represents a shock with mean one. The shock parameter $z_{t}$ follows the $\mathrm{AR}(1)$ process $\ln z_{t}=\theta \ln z_{t-1}+\varepsilon_{t}$ with autocorrelation $\theta$ and $\varepsilon_{t} \sim N\left(0, \sigma_{\varepsilon}^{2}\right)$. To capture the growth of agricultural productivity over the long term even before the Industrial Revolution, we let the efficiency parameter grow at rate $\gamma_{A}$, such that $\underline{A}_{A, t+1}=\left(1+\gamma_{A}\right) \underline{A}_{A, t}$. The shocks $\varepsilon_{t}$ should be interpreted as caused by weather conditions rather than changes in technology (as in Gilboy, 1932). ${ }^{4}$ Production becomes more efficient if more varieties of capital goods $j$ are available. These enter with the (constant) elasticity of substitution $(1+\epsilon) / \epsilon$, where $\epsilon>0$. Land is a fixed factor of production.

Manufacturing production is given by

$$
Y_{M}=A_{M}\left[\int_{0}^{J} v_{M}(j)^{\frac{1}{1+\epsilon}} d j\right]^{\eta(1+\epsilon)} N_{M}^{1-\eta}
$$

4 The abundance or shortage of seed as well as the effect of storage on price in periods following good or bad harvests causes the autocorrelation of output. (McCloskey \& Nash 1984). 
where $A_{M}$ is a productivity parameter, and $v_{M}(j)$ is the amount of capital variety $j$ used to produce manufacturing output in a representative final sector firm. ${ }^{5}$

\subsubsection{Capital}

Technological progress takes the form of a growing variety of machines available for production. There are $j$ types of capital. Each of them allows a firm to perform a specific task. The more specialized machinery is, the higher productivity in final goods production. ${ }^{6}$ As the number of varieties grows, machines that are better-suited to each production task become available.

Producers borrow capital from consumers, and pay interest at rate $r_{K}=R_{K}-\delta$. Producers replace depreciated capital while production occurs. ${ }^{7}$ The price of a variety is $p(j)$. There are $v(j)$ items of type $j$ machines available. Representative final sector firms then use $v_{A}(j)$ and $v_{M}(j)$ machines of type $j$ for food and manufacturing production, respectively. We assume that the subset of varieties that break (depreciate) in a given period is the interval $[(1-\delta) J, J]$ of capital varieties. ${ }^{8}$ The mass $\delta J$ of broken machines is replaced by producers while production occurs.

To start production, capital variety producers need to pay up-front cost $F$. Capital variety producer $\tilde{J}$ uses technology

$$
v(\widetilde{J})=A_{J}\left[\int_{0}^{J} v_{\widetilde{J}}(j)^{\frac{1}{1+\epsilon}} \mathrm{d} j\right]^{\eta(1+\epsilon)} N_{\widetilde{J}}^{1-\eta}-F
$$

where $A_{J}$ is a constant productivity parameter. Note that $j$ refers to machines existing in a given period, whereas $\tilde{J}$ stands for capital varieties that are currently produced as investment goods, becoming available for production in the next period. Like final sector firms, capital producers profit from a wider range of available capital inputs. ${ }^{9}$

Because of fixed costs, each capital variety is produced by a single firm. Since capital varieties are imperfect substitutes, their producers have monopolistic power. However, free market entry implies that each producer just recovers his unit cost and makes zero profits. We show in Appendix A.1 that in equilibrium each firm produces the same, fixed amount of capital varieties, given by $F / \epsilon$. Increasing investment leads to an extension of the range of capital varieties, while leaving the amount $v(j)$ of each

\footnotetext{
5 Due to constant returns in final production, we can assume without loss of generality that final sector firms are identical and have mass one. Individual firms' output, $Y_{A}$ and $Y_{M}$, and factor inputs are then equal to aggregate output and input in the final sector. Thus, a final sector firm represents aggregate final production.

${ }^{6}$ In the symmetric equilibrium, $v_{M}(j)=\bar{v}_{M}, \forall j$, and thus $Y_{M}=A_{M}{ }^{\eta \epsilon}\left(J \bar{v}_{M}\right)^{\eta} N_{M}^{1-\eta}$ Consequently, for a given amount of capital $J \bar{v}_{M}$, productivity is increasing in the number of available capital varieties $J$, and the extent of this externality is given by $\eta \epsilon$. Similarly, for agriculture production, the extent of the externality is given by $\phi \epsilon$.

7 This assumption becomes important in our simulation. It avoids that the capital stock falls until it finally reaches zero when consumers live at the subsistence level for a long time (Malthusian trap).

8 A simple way to motivate this assumption is to think of machines $j \in[0, J]$ as being ordered by age, with higher- $j$ subsets representing older machines. Due to their long use, or because of being incompatible with new machines, the highest- $j$ subset with mass $\delta$ breaks or becomes useless in each period, and is immediately repaired or replaced by machines of equal quality. New machines fill up the interval from below, increasing $J$, but leaving the age-ordering unchanged.

9 We deliberately deviate from the standard setup to simplify our analysis below, where we derive the model representation with two sectors and an aggregate externality.
} 
variety unchanged. This, together with symmetry in equilibrium, allows us to derive a simplified aggregate externality representation of the model, where investment goods are produced in the manufacturing sector.

\subsection{Model representation with aggregate externalities}

We show in Appendix A.4 that the production side of our model can be simplified to a two-sector model with externalities of aggregate capital in the style of Romer (1990). Technology is then given by

$$
\begin{array}{r}
Y_{A}=A_{A} K^{\phi \epsilon} K_{A}^{\phi} N_{A}^{\mu} L^{1-\phi-\mu} \\
Y_{M}=A_{M} K^{\eta \epsilon} K_{M}^{\eta} N_{M}^{1-\eta}
\end{array}
$$

where we introduced a more convenient notation for capital: $K_{A} \equiv J v_{A}$ and $K_{M} \equiv$ $J v_{M}$, representing the capital used by a representative firm in the respective sector. Investment, i.e., new capital varieties, are produced by the manufacturing sector, and the price of capital, $p_{K}$, is equal to the price of manufacturing output, $p_{M} \cdot{ }^{10}$ The productivity-enhancing effect of an increased variety of capital inputs is obvious in these standard Cobb-Douglas production functions. For a given $J=K$, the aggregate externality is the larger the larger the capital share $(\phi$ or $\eta)$ and the larger $\epsilon$ (i.e., the smaller the elasticity of substitution among capital varieties).

\subsection{Equilibrium and industrialization}

Equilibrium in our model is a sequence of factor prices, goods prices, and quantities that satisfies the intertemporal and intra-temporal optimization problems for consumers and firms. ${ }^{11}$ To fix ideas and show how industrialization happens in our model, we first present a simulation without consumption-dependent population dynamics. That is, we run our model with a positive constant birth rate and without shocks, such that all individuals survive. The next section explores how population dynamics - based on consumption-dependent fertility decisions and positive Malthusian checks in crisis periods - modify our results.

\subsubsection{Equilibrium and industrialization without population dynamics}

In this section we keep population growth constant in order to isolate the role of consumption preferences (structural change) and aggregate capital externality. We show that even with this reduced-form model we are able to replicate two important stylized facts of the Industrial Revolution in England - the initially small, but accelerating growth of industry output and structural change, i.e., an increasing share of industry in GDP. We simulate the model with a constant net birth rate, equal to the average rate in England $1700-1850, \gamma_{b}=0.8 \%$. In a non-stochastic setup, these parameters imply that consumption never falls below subsistence such that all individuals survive. We thus have neither a preventive (via birth rates) nor a positive (via death rates) Malthusian check. The corresponding results are shown in Fig. 1.

10 Since we have $p_{K}=p_{M}$ in the simplified model, the price terms in the Euler equation (5) simplify to $\left(p_{K, t+1} / p_{K, t}\right)^{\psi(1-\alpha)+\alpha}$, where the exponent is always positive.

11 A formal definition of the equilibrium is given in Appendix A.3. 

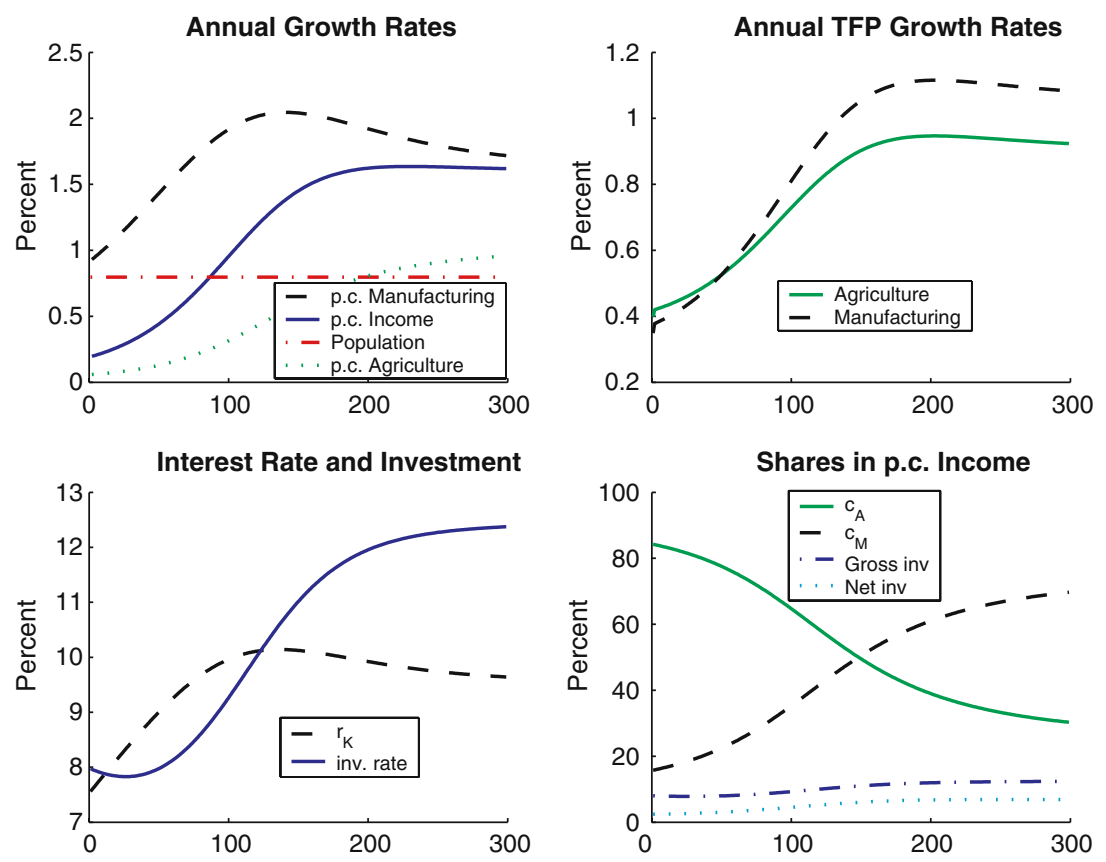

Fig. 1 Simulation results with constant population growth

Our simulation for England starts with the historical labor shares in agriculture and manufacturing in $1700\left(77 \%\right.$ and $23 \%$, respectively). ${ }^{12}$ Initially about half of manufacturing output is produced to replace depreciated capital, with the other half being used for consumption. Consumption exceeds the subsistence level so that all individuals survive and net population growth equals the birth rate $\left(\gamma_{N}=\gamma_{b}\right)$. Figure 1 shows that our model, even with constant birth rates, replicates the low, increasing growth rates observed in 18th century England. Growth is driven by the exogenous productivity progress in agriculture and by endogenous capital accumulation. Technological progress is fast enough to compensate the constant population growth of $0.8 \%$, so that p.c. income increases. ${ }^{13}$ Per capita consumption of agriculture grows much slower than p.c. output of manufacturing. This is explained by two mechanisms: First, as p.c. income grows, consumption expenditure shares shift from agriculture to manufacturing (as shown in the lower right panel). Once this transition is completed, industry growth rates stabilize above those of agriculture, which is explained by the second mechanism: due to their larger capital share, manufacturing firms profit relatively more from the aggregate externality. This is reflected in the upper right panel: Initially, agricultural and manufacturing TFP grow in tandem - the larger growth rate of p.c. industry output is thus initially solely due to its increasing demand share. When structural change comes to a standstill, TFP and all other growth rates stabilize

12 We use the same parameter values as in the full, calibrated model. Our conclusions with regard to structural change and the role of capital externalities are robust with respect to the choice of parameters.

13 This would not be the case if birth rates were substantially larger, since then p.c. capital would diminish at a rate that even the aggregate externality would not be able to compensate. 
at constant levels, with manufacturing TFP augmenting faster than agricultural TFP. The investment rate is low initially because p.c. consumption is close to subsistence. Investment then responds positively to growing income and interest rates. Eventually, when p.c. consumption has grown to a level well beyond subsistence and interest rates level off, investment rates stabilize at a higher level.

\subsubsection{Open economy considerations}

So far, we have assumed that the UK was a closed economy, with domestic conditions driving industrialization. Because of its role as a trading nation, this needs to be justified in the British case. Before it started to manufacture cotton goods with new technology, for example, Britain imported many of them from India. ${ }^{14}$ Eventually, Britain exported cotton goods and the like on a grand scale. Traditional interpretations of the importance of demand have assigned an important role to exports (Cole, 1973; Gilboy, 1932). This could also affect the logic of our argument - in some open economy models, lower initial agricultural productivity can increase the probability of industrialization since wages (and thus, prices of exports) are lower (Matsuyama, 1991). Here, we discuss how adding foreign demand and supply would change our basic setup.

The fact that British industrialization in cotton textiles replaced exports from India as such does not fundamentally alter our conclusions. Rising manufacturing productivity has two consequences in the model: higher p.c. income and lower prices. Both increase the demand for manufacturing output (the former through Engel's Law). In an open-economy framework, the price effect is even larger, because imports are replaced by home production and/or due to growing international demand. The falling relative price of manufacturing would also be expected to result in growing food imports.

An open economy setup, especially for the 18th century, must take into account the high cost of transportation. These made it (i) easier to replace the Indian competition in the UK and (ii) isolated the Indian producers from UK competition for some of the time. ${ }^{15}$ Table 2 shows that between 1750 and 1851, the share of exports - mainly of manufacturing products - in national output grew from about $15-20 \%$. As Mokyr (1977) stressed, there is no evidence that exports grew sufficiently rapidly to kick-start industrialization. We conclude that our closed-economy model can serve as a reasonable approximation. ${ }^{16}$

14 In the 1750s, Indian cotton piece exports to Britain were five times higher than British exports. Exports from India to Britain only collapsed after 1810 (Broadberry \& Gupta, 2005b, Table 6).

15 Initially, Indian exports become uncompetitive in Britain as the UK switches to industrialized production. Home production in India remains competitive while transport costs raise the price of UK cotton goods there. Eventually, Indian production of cotton goods for home demand falls as UK imports become cheaper due to falling transport cost (Broadberry \& Gupta, 2005b).

16 Total output, $Y$, approximately quadrupled between $1750(t=0)$ and $1850(t=T)(\mathrm{Crafts}, 1985)$. From simple growth accounting, we have: $\frac{Y^{T}-Y^{0}}{Y^{0}}=\left[s_{E}^{T} \frac{Y^{T}}{Y^{0}}-s_{E}^{0}\right]+\left[\left(1-s_{E}^{T}\right) \frac{Y^{T}}{Y^{0}}-\left(1-s_{E}^{0}\right)\right]$ where the parentheses indicate output growth due to exports and domestic demand, respectively. Let the share of exports grow from $s_{E}^{0}=15 \%$ to $s_{E}^{T}=20 \%$, as in Table 2 . Then, $78 \%$ of growth is due to domestic demand, while exports account only for $22 \%$. 
Table 2 International trade in England 1700-1851

Source: Crafts (1985), Table 6.6 and 7.1. Authors'calculation assuming balanced trade. All numbers in per cent

* Number for 1760

\begin{tabular}{llll}
\hline Year & $\begin{array}{l}\text { Exports / } \\
\text { Output }\end{array}$ & $\begin{array}{l}\text { Manufactures } \\
\text { Exports /Output }\end{array}$ & $\begin{array}{l}\text { Food Imports / } \\
\text { Output }\end{array}$ \\
\hline 1750 & $14.6^{*}$ & 11.0 & 4.5 \\
1801 & 15.7 & 13.8 & 6.1 \\
1831 & 14.3 & 13.0 & 3.9 \\
1851 & 19.6 & 15.9 & 7.2 \\
\hline
\end{tabular}

\subsubsection{Inequality}

To capture one particular feature of the pre-modern world highlighted by Fogel (1994), we also consider the economic contribution of the bottom $20 \%$ of the income distribution. According to Fogel, in eighteenth-century France, the poorest $20 \%$ did not receive enough food to perform more than a few hours of work a day. We model such an outcome by assuming that, if average consumption falls below subsistence, members of the workforce that will die because of malnutrition will also not be able to work. This is clearly too optimistic - even without starvation, many members of the workforce will be malnourished. When harvest failures occur, the effective workforce will shrink - except in England, which provided generous support to the poor via outdoor relief, especially during the years of high prices in the late eighteenth century. In the other two countries we consider - France and China - we assume that there is no redistribution.

\subsubsection{Population dynamics}

Having summarized the basic properties of the economy, we now add population dynamics. At low levels of productivity, the economy is Malthusian. As agricultural productivity increases, population expands. As land-labor ratios fall, living standards decline and return to their earlier level. If times are bad, starvation can cause sharp declines in population size. We show how certain features of the demographic regime can make the escape from the Malthusian trap possible. In particular, we demonstrate how a low-pressure regime with limited fertility increases the chances for sustained growth.

The size of the representative household (or population) $N$ increases by a factor of $g_{b}(\cdot)$ at the end of each period:

$$
N_{t+1}^{*}=g_{b} N_{t}
$$

where $N_{t}^{*}$ is the beginning-of-period population, whereas $N_{t}$ stands for the population that survived period $t$. The exact growth factor depends on the demographic regime. At one extreme ("high pressure regime"), we assume a constant birth rate $g_{b}$. Here, population returns to equilibrium after negative shocks through more deaths (e.g., Malthus' positive check). Alternatively ("low pressure regime"), the birth rate depends positively on real consumption, $g_{b}\left(c_{t}\right) .{ }^{17}$ This is because the European marriage pattern regulated population-wide fertility by changing marriage rates. In bad times, people married later, and fewer women ever married. Within marriage, there

17 Concretely, $c_{t}$ denotes per-capita consumption of agriculture and manufacturing goods, that is, $c_{t}=c_{A, t}+c_{M, t}$.

글 Springer 
were no signs of fertility-limitation. In this way, population is balanced by the operation of both the positive and the preventive check.

We assume that if consumption per head falls below $\underline{c}$, only a subset of the population survives. The probability of survival depends on the severity of the nutrition crisis, measured by the ratio of $c_{t}$ to $\underline{c}$ :

$$
g_{s}\left(c_{t}\right)=\frac{N_{t}}{N_{t}^{*}}=\min \left\{\frac{c_{t}}{\underline{c}}, 1\right\}
$$

With severe harvest failures, population falls, and starving individuals consume their capital. They die when they have exhausted it. ${ }^{18}$

It could be argued that population growth should only depend on income in terms of agricultural goods (as in Strulik, 2006). We consider our approach more intuitive, since goods produced in urban centres were clearly an important part of the consumption bundle even for poor people (King, 1997) before the Industrial Revolution, as reflected by urbanization rates. However, the basic mechanism enabling sustained growth is robust to changing the population growth function in the manner of Strulik (2006). Since fertility responds only to one part of income, population growth is slower. The positive externality has a smaller effect. Hence, TFP and output growth also slow down. However, industrializations still occur with a high frequency. ${ }^{19}$

Population growth $\gamma_{N, t}$ is a function of economic conditions:

$$
\gamma_{N, t}=\frac{N_{t+1}^{*}-N_{t}^{*}}{N_{t}^{*}}=g_{b} g_{s}\left(c_{t}\right)-1
$$

where $g_{b}$ depends on $c_{t}$ or is a positive constant.

The birth function $g_{b}(\cdot)$ is crucial for the escape from the Malthusian trap. ${ }^{20}$ If birth rates at low levels of consumption are also low, and the response of births to improving conditions is small, productivity growth can translate into growth of per-capita income (despite the fact that population grows). This will be the case if $g_{b}(\cdot)$ is relatively flat at $\underline{c}$.

Where $g_{b}(\cdot)$ is a positive constant, escaping the Malthusian trap is nearly impossible. If the constant birth rate $g_{b}$ exceeds productivity growth, resources are not sufficient to nurture everyone and the surviving population remains trapped at the subsistence level. ${ }^{21}$ We will from now on use the full model, with population dynamics. Next, we describe the economic effects of demographic interactions, contrasting the "low pressure" and the "high pressure" regimes. In this setup, we show how fertility limitation helps the escape from the Malthusian trap.

Figure 2 shows population growth as a function of capital per head $(k)-$ in the left panel for the low-pressure regime and in the right panel for the high-pressure regime. Capital stock per head corresponds to a certain level of per capita income, given a certain level of TFP. As incomes and consumption improve, birth rates $\gamma_{b}$ increase in the low-pressure regime, while they are constant in the high-pressure regime. Above

\footnotetext{
18 Diamond (2004) describes how the Norse colony in Greenland collapsed after years of worsening climatic conditions, until farmers started to eat their calves and seed corn.

19 The growth rate of output per capita over 150 periods with the Strulik assumptions is $0.34 \%$ instead of $0.56 \%$ in the deterministic baseline simulation.

20 See Appendix A.7 for our calibration of the birth function for England.

21 In our calibrated model for China in 1700 , for example, the constant birth rate is $4 \%$, while deaths occur with rate $3.2 \%$, implying a net population growth of $0.8 \%$ p.a.
} 
Low-pressure Regime

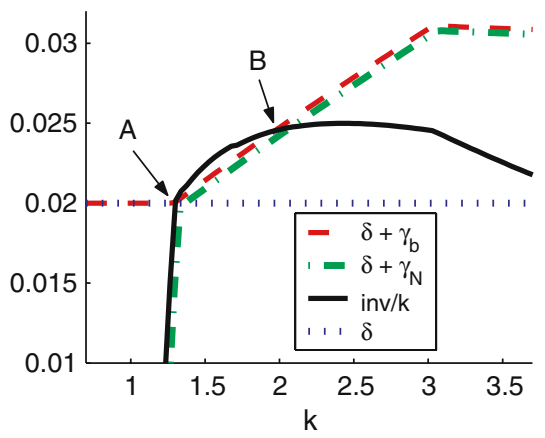

High-pressure Regime

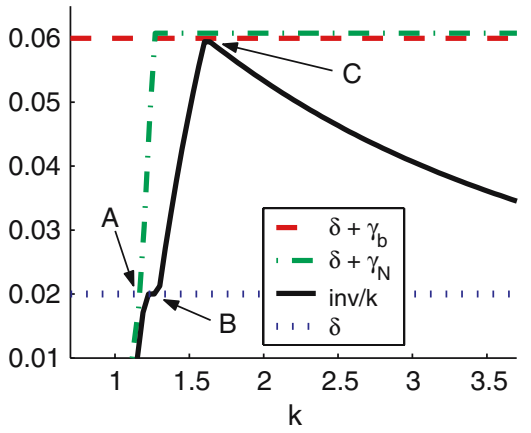

Fig. 2 Population dynamics for England and China

point A, income rises with $k$ such that death rates (given by $\gamma_{b}-\gamma_{N}$ ) dwindle to zero. The solid black line shows the gross rate of capital formation, inv/ $k$, where real investment is $i n v=(y-e) / p_{K} \cdot{ }^{22}$ The growth rate of capital stock per capita is given by the difference between inv $k$ and effective depreciation $\left(\delta+\gamma_{N}\right)$. In equilibrium with constant $k$, the capital-diluting effects of population growth and depreciation offset each other: $\left(\delta+\gamma_{N}\right) k=(y-e) / p_{K}$.

We begin by analyzing the low-pressure regime. To the left of point A, consumption is below subsistence $(c<\underline{c})$, and due to the crisis no new individuals are born $\left(\gamma_{b}=0\right)$. Investment just replaces depreciation. ${ }^{23}$ Net population growth $\gamma_{N}$ is negative such that the increasing land-labor ratio implied by falling population finally drives the economy back to an equilibrium at point $\mathrm{A}$. At point $\mathrm{A}$, consumption is at subsistence $(c=\underline{c})$; the birth rate is zero. Point $\mathrm{A}$ is an unstable equilibrium. For higher levels of $k$, incomes improve and investment rises. Eventually, declining marginal returns to capital force down the $i n v / k$ curve. The new (stable) equilibrium is point $\mathrm{B}$, which combines constant $k$ and a growing population.

In the high pressure regime, the economy behaves differently. The right panel of figure 2 depicts the interactions of demographic growth, investment, and output. For low levels of capital, there is also starvation, as in England. Point A now is a stable equilibrium with $c<\underline{c}$, and birth rates that are offset by death rates. However, with capital slightly higher than at point $\mathrm{A}$, death rates fall quickly until the economy reaches point $\mathrm{B}$, where $c=\underline{c}{ }^{24}$ Now, death rates are zero, and demographic growth becomes very fast. Consumers respond to this rapid population growth by investing massively, in order to ensure minimal consumption tomorrow, when they expect to share their income with many others. This explains the steep slope of the inv/ $k$ curve to the right of point B. However, despite saving all income above subsistence, demographic growth is too rapid - capital-labor ratios fall, driving the economy back to point $\mathrm{A}$. If the economy reaches point $\mathrm{C}$, capital-labor ratios stabilize, as the capital stock expands at the same rate as population. However, point $\mathrm{C}$ is not a stable

\footnotetext{
22 This is gross of depreciation.

23 This follows from our assumption that producers immediately replace depreciated capital varieties. Without this assumption consumers would choose not to repair the capital stock and even consume out of it if consumption falls below subsistence.

24 Between $\mathrm{A}$ and $\mathrm{B}$, net investment is zero because consumption is below subsistence. 
equilibrium since a small negative shock will drive the economy back to point $\mathrm{A}$. To the right of $\mathrm{C}$, investment falls rapidly, as marginal returns decline and saving rates reduce.

Only the low pressure regime is likely to generate endogenous TFP growth. At point $\mathrm{B}$ in the low-pressure regime, total capital is growing with population. Because of the aggregate externality, this generates TFP growth. In Fig. 2 this would be equivalent to a shift up and to the left of the inv/ $k$ line - for any given capital stock, incomes are now higher. There is also an outward shift of the birth schedule, since higher incomes stimulate higher birth rates and sustain a larger population at the same p.c. capital level. The combined effect under our calibration leads to a point $\mathrm{B}^{\prime}$ that is markedly higher, and further to the right - TFP growth produces a new equilibrium $\mathrm{B}^{\prime}$ that is more capital intensive, has higher incomes, and more rapid population growth. This explains the gradual acceleration of growth rates in the low pressure regime.

In the high pressure regime, endogenous growth is not impossible but highly unlikely. Higher TFP simply shifts the investment schedule to the left - for any given level of capital, potential consumption is higher, but so is population growth. Higher productivity leads to a bigger population, with unchanged income at $\mathrm{A}$. If the (constant) birth rate under the high-pressure regime was low enough, growth could occur, because the investment schedule would eventually cross the line given by $\delta+\gamma_{N}$. This would create a stable equilibrium point $\mathrm{C}$, similar to point $\mathrm{B}$ in the low-pressure regime. The maximum rate of population increase that does not exhaust investment possibilities varies with starting conditions. In our calibration, a country with an initial non-agricultural labor share of $23 \%$ (equivalent to Britain's in 1700) could have sustained population growth rates of up to $3.7 \%$ because of high initial income; a country with only $10 \%$ in non-agricultural occupations (as China in 1700) could not have coped with rates higher than $0.6 \%$ without foregoing its chances to industrialize. ${ }^{25}$

\section{Calibration and simulation results}

In this section we explain the calibration of our model, and simulate it with and without shocks to agricultural productivity. We then derive the probability of industrialization in England, France, and China. In addition, we illustrate what would have happened to the English economy had it operated under a high-pressure demographic regime instead. Finally, we simulate the model without the kind of redistribution that the Poor Law provided.

\subsection{Calibration}

We normalize initial population of England to unity $\left(N_{0}=1\right)$ and choose land $L=8$ such that its rental rate is $5 \%$. We choose initial agricultural TFP and aggregate capital to match the historical labor share in agriculture of $77 \%$ in $1700 .{ }^{26}$ Aggregate capital $K$ influences TFP via the externality. In order to identify the initial conditions for $A_{A, 0}$ and $K_{0}$, we re-normalize the production functions, dividing by $K_{0}^{\phi \epsilon}$ in agriculture

25 These are the results for non-stochastic simulations. In calibrations with shocks, there would be a distribution of industrialization outcomes for each demographic growth rate. See Section 4.4.

26 We derive this figure from Craft's (1985) original numbers by leaving out other sectors than agriculture and manufacturing and re-normalizing the sum of these two sectors' labor shares to unity. 


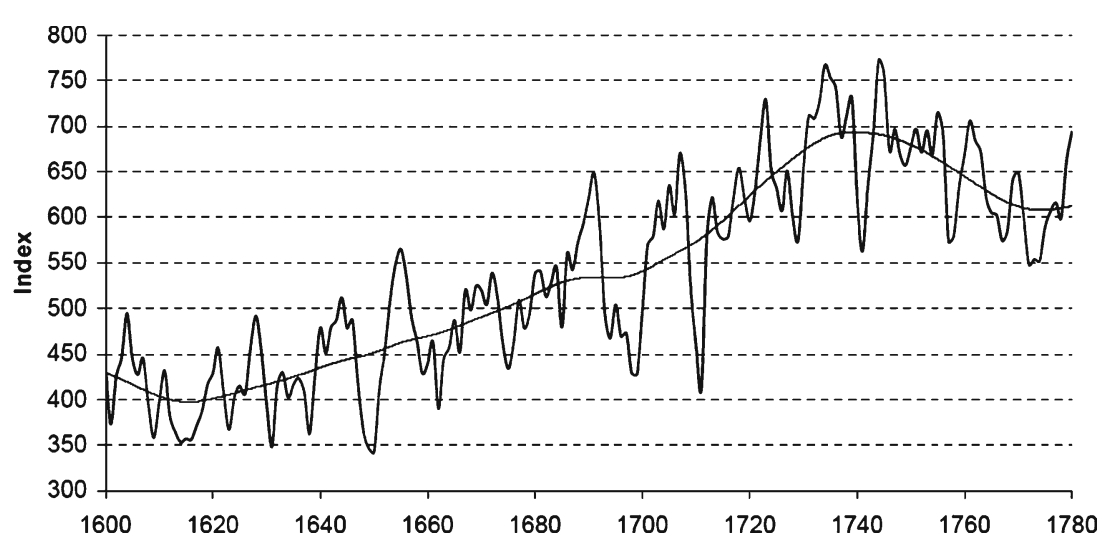

Fig. 3 Real wage fluctuation and trend

and by $K_{0}^{\eta \epsilon}$ in manufacturing. This means that the aggregate externality term has value one in the initial period. ${ }^{27}$ We choose $A_{M}$ such that the price of manufacturing products is double the price of agriculture products, i.e., $p_{M}=2$. $^{28}$ This procedure gives $A_{A, 0}=0.517$ and $A_{M}=0.359$. Given these parameters, we derive a low level of capital, $K_{\min }$, at which consumption is at the subsistence level $(c=\underline{c})$. Below this level, only agricultural goods are consumed, and aggregate capital does not influence TFP. The externality works only if $K \geq K_{\min } \cdot{ }^{29}$ In other words, it is not before the "wave of gadgets" (Ashton, 1964) arrives that the aggregate externality begins to matter quantitatively.

In the centuries before 1700 , labor productivity grew at an average rate of $0.15 \%$ per year (Galor, 2005). Because agriculture was the dominant sector, we assume an exogenous growth rate of TFP growth in the sector of $\gamma_{A}=0.15 \%$.

The magnitude and persistence of shocks in the agricultural sector is derived from real wage data for England, 1600-1780 (Wrigley et al., 1997). With fixed labor supply and agriculture the dominant sector, these productivity shocks have an immediate knock-on effect on real wages in the economy. This is especially true since wages were largely fixed in nominal terms, and most of the variation in the Phelps-Brown/Hopkins wage series results from changes in agricultural prices (Wrigley et al., 1997). We therefore use the wage $z_{t}$ as an indicator of the size of shocks. Figure 3 shows the real wage index and the corresponding Hodrick-Prescott-trend. ${ }^{30}$

27 This normalization does not change any of the features of our model. In fact, dividing $K$ by $K_{0}$ is equivalent to re-defining $A$ in the production function. For example, let the original production function be $Y_{M}=A_{M}^{*} K^{\eta \epsilon} K_{M}^{\eta} N_{M}^{1-\eta}$. Then choose $A_{M}$ such that $A_{M}^{*}=A_{M} / K_{0}^{\eta \epsilon}$. This gives the new production function $Y_{M}=A_{M}\left(K / K_{0}\right)^{\eta \epsilon} K_{M}^{\eta} N_{M}^{1-\eta}$.

28 Different values of this parameter change our results only slightly. They do so at all because $p_{M}=p_{K}$, and a different price of capital implies a different real capital stock.

29 The aggregate externality thus takes on the values $\left[\max \left\{\frac{K}{K_{0}}, \frac{K_{\min }}{K_{0}}\right\}\right]^{\phi \epsilon}$, in agriculture and $\left[\max \left\{\frac{K}{K_{0}}, \frac{K_{\min }}{K_{0}}\right\}\right]^{\eta \epsilon}$ in manufacturing.

30 The standard deviation of real wages is very similar to the standard deviation of agricultural output in later years.

Springer 
The magnitude of shocks is derived from analyzing the autocorrelation of wages. We estimate $\ln z_{t}=\theta \ln z_{t-1}+\varepsilon_{t}$, which produces $\theta=0.60(\mathrm{t}=10.15)$ and $\sigma_{\varepsilon}=0.075$. The autocorrelation of shocks is high, and the series is volatile.

For the baseline model, we calibrate the parameters $(\mu, \phi, \eta, \epsilon)$ to fit average factor shares for the period 1700-1850. In agriculture, we use $\mu=0.4$ for labor, $\phi=0.25$ for capital, and the remaining 0.35 for land. This is similar to the 40-20-40 split suggested by Crafts (1985), and is almost identical with the average in Stokey's (2001) two calibrations. In manufacturing, we use a capital share of $\eta=0.35$. $^{31}$

We normalize the minimum food consumption $\underline{c}$ to unity. For low income levels, Eq. (2) implies that all expenditure goes to agriculture. With higher incomes, the expenditure share converges to $\alpha$. We take expenditure data from Crafts (1985), using the same re-normalization as for labor shares. The agriculture consumption share falls from $65 \%$ in the 18 th to $30 \%$ at the end of the 19 th century. We thus use $\alpha=0.3$. Next, we need to choose $\psi$, i.e., the inverse of the intertemporal elasticity of substitution. In the literature, values between 1 and 4 have been used. We employ $\psi=1$, which implies log-utility, because this matches the elastic supply of savings during the Industrial Revolution. ${ }^{32}$ In order to capture the low initial share of investment ( $4 \%$ in $1700,6 \%$ in 1760 , taken from Crafts 1985 , Table 4.1 ), we need a low discount factor, and use $\beta=0.93$ and depreciation rate $\delta=0.02$.

The aggregate externality plays a central role in our model. The extent of the externality is given by $\phi \epsilon$ in agriculture and by $\eta \epsilon$ in manufacturing production. In manufacturing, total factor productivity is given by $A_{M}\left(K / K_{0}\right)^{\eta \epsilon}$, where the first term and $K_{0}$ are constant. Growth of manufacturing TFP is

$$
\gamma_{T, M}=\eta \epsilon \gamma_{K}
$$

Total factor productivity in agriculture is determined by $A_{A}\left(K / K_{0}\right)^{\phi \epsilon}$, where the first term grows at the exogenous rate $\gamma_{A}$ :

$$
\gamma_{T, A}=\gamma_{A}+\phi \epsilon \gamma_{K}
$$

Crafts (1985) provides growth accounting figures for England, 1700-1860. We present the corresponding TFP and aggregate capital growth rates in Fig. 3. If the aggregate externality link from capital to TFP in our model represents historical facts, we would expect a linear relationship between the growth rates of the two variables. Figure 4 lends some support to this supposition. ${ }^{33}$

Average annual growth rates are $\bar{\gamma}_{K}=1.17 \%$ and $\bar{\gamma}_{T}=0.48 \%$ for capital and TFP, respectively. There is no agreement in the literature as to whether productivity growth in agriculture was faster, slower or equal to productivity growth in modern sectors. For example, Crafts (1985: 70-89) concluded that productivity growth in agriculture was rapid, and in some periods surpassed manufacturing productivity growth. On the

\footnotetext{
31 Stokey (2001) uses a calibration for an energy-capital aggregate with the average share of 0.4.

32 The higher intertemporal elasticity of substitution implied by the smaller $\psi$ means that consumers' savings react more elastically to changes in the interest rate. On the high elasticity of savings, see Allen (2005b).

33 Of course, we do not claim here that our model is the only explanation of the relationship observed in the growth accounting data. In fact, the causality could also go the other way around - from exogenous TFP growth to capital accumulation. However, what matters for our calibration is the linearity of the relationship, while we suppose the direction of causality to be from K to TFP, along the main line of our argument relating to an increasing number of available capital varieties.
} 


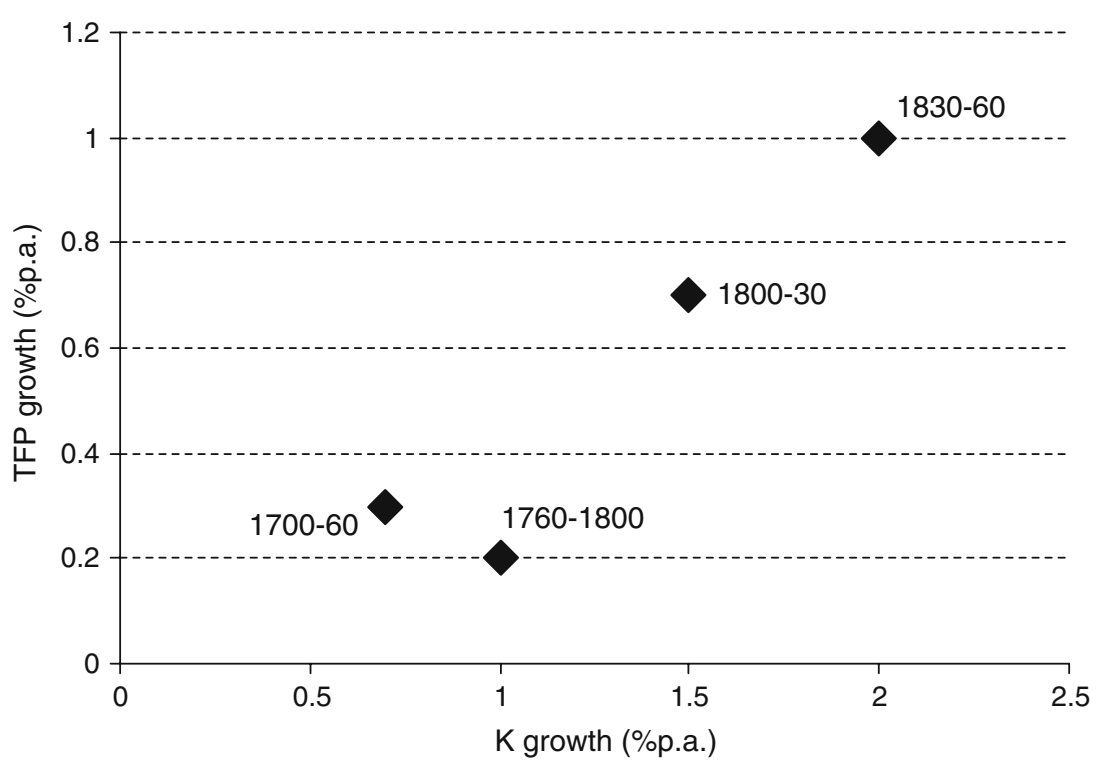

Fig. 4 Annual growth rates of TFP and aggregate capital. Source: Derived from Crafts (1985) and Crafts \& Harley (1992)

other hand, Clark (2003b) argued that they took a long time to materialize. We therefore assume that the growth of labor productivity was broadly speaking the same in manufacturing and agriculture. Thus, aggregate TFP growth is equal to sectoral TFP growth, and we can estimate the relationship (14) using the data represented in Fig. 3. A weighted least-square estimation (with the length of periods serving as weights) without constant yields the estimate $\widehat{\eta \epsilon}=0.44(t=7.26) .{ }^{34}$ With $\eta=0.35$, this implies $\epsilon=1.25$, corresponding to an elasticity of substitution across capital varieties of 1.8. There is an easy way to check the consistency of this calibration with other calibrated variables: we use the observed $\bar{\gamma}_{K}$ and $\bar{\gamma}_{T}$ together with the calibrated $\gamma_{A}, \phi$, and $\epsilon$ to check (15). The result is $0.51 \%$ on the right-hand side, which corresponds well to $\bar{\gamma}_{T}=0.48 \% .{ }^{35}$ For the observed growth of aggregate capital 1700-1860, our calibration thus implies very similar TFP growth rates in manufacturing and agriculture, where the latter also includes an exogenous term.

We employ a birth schedule $g_{b}(c)$ based on the historically observed co-movement with wages (cf. Figure 8). ${ }^{36}$ It is derived from fitting the empirical data with a spline regression, as described in detail in Appendix A.7. For the demographic regime with positive Malthusian check, $g_{b}$ is a constant equal to the net birth rate.

We summarize the calibration parameters in Table 3.

\subsection{The industrial revolution in England}

How well does the calibrated version of our model fit the historical data for England? We start in 1700 and run the simulation for 150 years. Figure 5 compares the non-sto-

\footnotetext{
34 Another possibility is to take average values instead of running a regression. The result is very similar: $\bar{\gamma}_{K} / \bar{\gamma}_{T}=0.41$.

35 Our choice of the capital shares $\phi$ and $\eta$ is crucial for this result.

36 We use the data from Wrigley et al. (1997).

型 Springer
} 
Table 3 Baseline calibration

\begin{tabular}{lll}
\hline Symbol & Interpretation & Value \\
\hline Parameters & Agriculture expenditure share & \\
$\alpha$ & Consumer discount rate & 0.3 \\
$\beta$ & CRRA utility parameter & 0.93 \\
$\psi$ & Capital share in agriculture & 1 \\
$\phi$ & Labor share in agriculture & 0.25 \\
$\mu$ & Capital share in manufacturing & 0.4 \\
$\eta$ & Parameter for capital variety substitutability & 0.35 \\
$\epsilon$ & 1.25 \\
$c$ & Subsistence food consumption & 1 \\
$L$ & Land & 8 \\
$\delta$ & Capital depreciation rate & 0.02 \\
$\gamma_{A}$ & Growth of agriculture technology & 0.0015 \\
$\theta$ & Autocorrelation of shocks to agriculture & 0.6 \\
$\sigma_{\varepsilon}$ & Standard Deviation of shocks to agriculture & 0.075 \\
$A_{M}$ & Manufacturing technology parameter & 0.359 \\
Initial Conditions & \\
$N_{0}$ & Initial population & 1 \\
$A_{A, 0}$ & Initial agriculture technology parameter & 0.517 \\
$K_{0}$ & Initial aggregate capital & 1.718 \\
$K_{\min }$ & Capital at which $c=\underline{c}$ & 1.308 \\
\hline
\end{tabular}

chastic simulation and historical facts. Over the period as a whole, population triples, while real per capita income doubles - mainly due to the increase of manufacturing output. Importantly, growth rates of output and TFP are initially low but increase over time. The model does well in capturing one of the key characteristics highlighted by economic historians in recent years - the slow rate of productivity and output growth (Crafts and Harley, 1992). Also, output of agricultural products increases only slightly in our model, in line with the historical record (Allen, 1992), Table 8.7].

The behavior of population and real manufacturing output is captured well by the model, even if we overestimate the growth of the latter somewhat. Initially, investment mainly replaces depreciated capital. Even with a low depreciation rate of $\delta=0.02$, this implies an investment share of about $6 \%$, which exceeds the historical estimate for $1700 .{ }^{37}$ Our simulation replicates the rise of the investment rate during the following decades, but falls short of its full extent. One possible reason is changes in $\delta$. Depreciation rates may have increased over time because machines became increasingly complex and technological obsolesence rendered useable equipment unprofitable. Real investment per capita grows by a factor of 3.5, which is accounted for by an increasing investment rate, growing income, and a falling relative price of capital (dropping by $25 \%$ ). Population growth peaks around 1820, which coincides with the historical facts. TFP in agriculture and manufacturing is growing at similar rates. Agriculture benefits from exogenous growth $\left(\gamma_{A}=0.15 \%\right)$; manufacturing from the greater externality resulting from its higher capital share. Payments to land become less important in total output, while capital and labor gain about $5 \%$ each. Stokey (2001) shows that labor and capital gained a larger share of the pie, and that land lost about $10 \%$ points of aggregate income - yet the gains for capital in our model are somewhat smaller than the historical record suggests.

37 The corresponding equations are $I=\delta p_{K} K$ and $p_{K} R_{K} K=\tau Y$, where $\tau$ is the aggregate capital share. For $\tau \simeq 0.3$ and $R_{K} \simeq 0.1$ (the approximate values in 1700) this yields $I / Y=\delta \tau / R_{K} \simeq 0.06$. 
Population

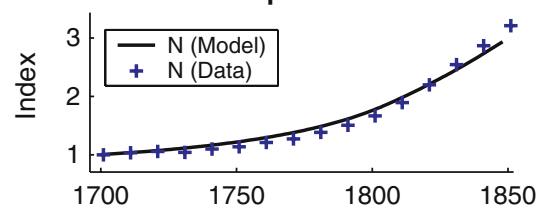

Real p.c. Industry Output $(\mathbf{1 7 8 0}=1)$
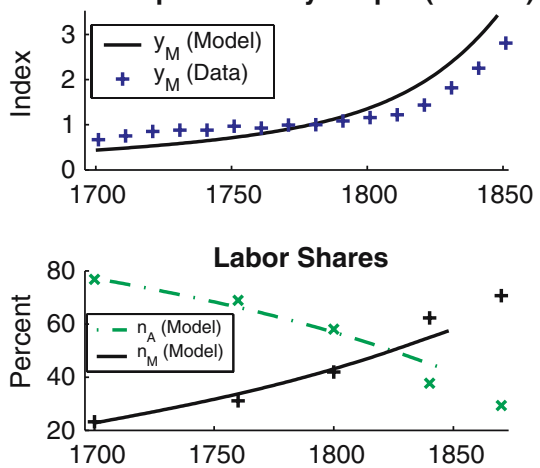

p.c. Capital

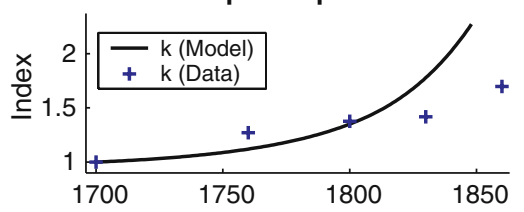

Real p.c. Income

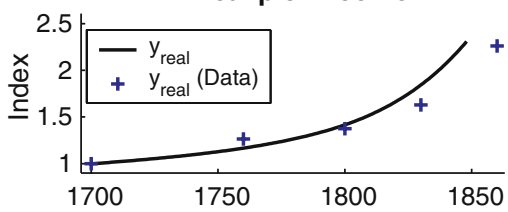

Investment Rates

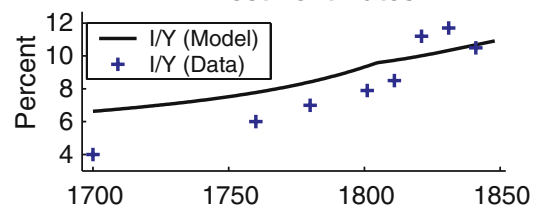

Shares in GDP

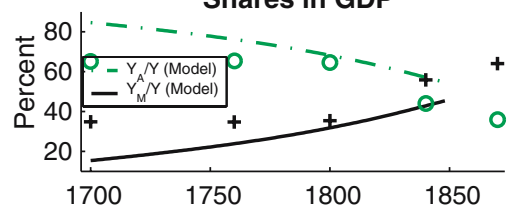

TFP Growth vs. Capital Growth

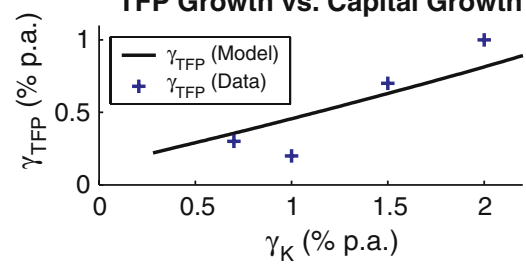

Fig. 5 Simulation and data for England 1700-1850. Sources: Allen (1992), Crafts (1985), Wrigley and Schofield (1981)

Employment shares in agriculture and manufacturing fit the data well, while the model overestimates the income share of agriculture. ${ }^{38}$ One reason for this is hidden unemployment in agriculture - many workers in the English fields in 1700 may have added little to output. With the beginning of the Industrial Revolution around 1780, many of these laborers migrated to the cities. For these later years, the fit with our model is markedly better. Finally, TFP growth in our simulation fits the actual data well. ${ }^{39}$

\subsection{Sensitivity analysis}

In the following we provide robustness checks of our model. We start from the baseline calibration and sequentially change key parameters (similar to Lagerlöf, 2006). The results are summarized in Table 4. Our baseline used an exogenous rate of

38 We derive the historical employment and income shares based on the numbers in Crafts (1985: 62). We exclude the service sector, renormalize the percentages and interpolate to find the data for $1700-1860$.

39 The exception is the unusually low TFP in the late eighteenth century, when negative shocks such as the Napoleonic Wars may have made a big difference (Temin \& Voth, 2005; Williamson, 1984). 
Table 4 Sensitivity analysis

\begin{tabular}{lllll}
\hline Changed parameters & $y_{1850} / y_{1700}$ & $k_{1850} / k_{1700}$ & $N_{1850} / N_{1700}$ & $N_{M, 1850} / N_{1850}$ \\
\hline none [Baseline Model] & 2.31 & 2.28 & 2.93 & 0.57 \\
$\gamma_{A}=0, \epsilon=1.5$ & 1.99 & 1.98 & 2.40 & 0.50 \\
$\phi=0.2, \eta=0.5, \epsilon=0.88$ & 2.61 & 3.11 & 3.18 & 0.45 \\
$\psi=4$ & 2.40 & 2.33 & 3.17 & 0.57 \\
\hline
\end{tabular}

agricultural TFP growth, $\gamma_{A}=0.15 \%$ p.a. In the first sensitivity check, we set this to zero. In order to fit the observed relationship between capital and TFP growth (Fig. 4), we consequently re-calibrate $\epsilon$, obtaining a higher value. ${ }^{40}$ Thus, some of the growth that was previously exogenous is now the result of a stronger aggregate externality. With all other parameters identical with the baseline calibration, the simulation yields slower growth, capital accumulation, and structural change when $\gamma_{A}=0$. The difference with our baseline is however relatively minor.

In the second alternative specification, we change the capital shares in agriculture $(\phi=0.2)$ and manufacturing $(\eta=0.5)$. This represents the $\phi$ suggested by Crafts (1985) and the $\eta$ used by Stokey (2001). ${ }^{41}$ The larger aggregate capital share now implies a smaller $\epsilon{ }^{42}$ Since capital is more important in aggregate production, it generates more externalities; $\epsilon$ thus has to be smaller to maintain the observed relationship between capital and TFP growth. ${ }^{43}$ The simulation results shown in the third row of Table 4 reveal that the larger manufacturing capital share leads to accelerated growth of output, population, and capital stock, compared to the baseline. Again, the difference is not very large. Because of its greater capital share, the manufacturing sector now profits more from aggregate capital accumulation, and TFP rises relative to agriculture. The relative price of $p_{M}$ thus falls. Since $p_{M}=p_{K}$, the price of investment also falls. Consequently, a given investment ratio leads to more capital deepening. Faster capital accumulation, on the other hand, implies more rapid TFP growth, creating a virtuous circle.

Our final sensitivity check examines the elasticity of intertemporal substitution, $1 / \psi$. The usual range for the CRRA parameter $\psi$ is between 1 and 4 . While we used $\psi=1$ in the baseline, we now choose $\psi=4$. The last row of Table 4 shows that growth and structural change occur somewhat faster than in the baseline simulation. This might be considered counterintuitive. In one-sector growth models, the growth rate typically depends negatively on $\psi$. In a two-sector model, the relative price of manufacturing output can change. The baseline simulation has $p_{M}$ rising initially, and

\footnotetext{
40 In the baseline calibration, Eqs. (14) and (15) give $\gamma_{T, M} \simeq \gamma_{T, A} \simeq 0.51 \%$ p.a. Thus, total TFP growth $\gamma_{T} \simeq 0.51$ in the baseline case. We now use this figure to derive $\epsilon$ for the case $\gamma_{A}=0$. Given that the average share of agriculture in GDP was about $60 \%$ between 1700 and 1850 [abstracting from the service sector, which we do not model], the corresponding approximation $\gamma_{T} \simeq 0.6 \gamma_{T, A}+0.4 \gamma_{T, M}=$ $0.6 \phi \epsilon \bar{\gamma}_{K}+0.4 \eta \epsilon \bar{\gamma}_{K}$ implies $\epsilon \simeq 1$.5. Note that we cannot obtain $\gamma_{T, M}=\gamma_{T, A}$ if $\gamma_{A}=0$ and $\phi \neq \eta$.

41 To ensure comparability, we use her figure for the "capital-energy aggregate in the manufacturing sector."

42 Since $\gamma_{A}>0$, we use the same procedure as in the baseline calibration. We obtain $\epsilon=0.88$ from $\widehat{\eta \epsilon}=0.44$ and $\eta=0.5$. Note that for $\bar{\gamma}_{K}=1.17 \%$ we now have $\gamma_{T, M}>\gamma_{T, A}$, which deviates somewhat from the historical record.

43 We also need to re-calibrate initial TFP in agriculture and manufacturing as well as the initial capital stock. These are $A_{A, 0}=0.505, A_{M}=0.325$, and $K_{0}=1.79$, respectively.
} 
then falling steadily. ${ }^{44}$ In the baseline simulation with log-utility, the change in $p_{M}$ has no impact since the income and substitution effect cancel each other. With $\psi>1$, however, the income effect is relatively stronger. An (expected) increase in the price of consumption lowers today's expenditure and yields an increase in investment. Consequently, with $\psi=4$ the investment rates at the beginning are larger than in the baseline simulation, which explains the faster growth. ${ }^{45}$

\subsection{The role of chance}

Adding shocks to our model produces a significant dispersion of industrialization outcomes. It also slows development on average. In the stochastic simulations, a negative shock lowers both total income and investment. Moreover, large negative shocks lead to starvation and a net decline of population and capital stock, reducing the scope for the capital externality to work its wonders. There is also a second, more subtle effect: In the stochastic simulation, a positive shock to agricultural productivity causes a surge in expenditure, and more demand for manufacturing goods. Investment increases. However, the positive shock to agricultural productivity also makes food much cheaper. This produces an increase in the relative price of capital so that a given quantity of savings translates into relatively less capital accumulation. By contrast, in the deterministic simulation, the relative price of capital (produced in manufacturing) does not change quickly, because agricultural and manufacturing TFP grow in tandem.

Figure 6 shows the results of 1,000 model runs, starting with the parameters for 1700 , and simulating the model over 150 periods. ${ }^{46}$ The share of the workforce in manufacturing is our indicator of industrialization. It varies substantially across simulations, and so does the growth rate.

The results lend support to Crafts's (1977) argument that historical accident may have contributed to England industrializing first - the range of outcomes is wide. Also, the actual historical performance of the English economy is in the better half of possible results. Most likely, England would have had markedly lower per capita income and experienced an even slower shift out of agriculture - many simulation values for 1850 are as much as one third lower. A run of good years in the 1740 s aided the transformation, by producing higher incomes. This then led to higher demand for manufactured products (Gilboy, 1932). To our knowledge, this is the first calibration exercise that demonstrates, based on a fully specified model, the extent to which Britain's industrial dominance in 1850 was the result of a lucky draw. Analogously, it could be argued that other, unmodelled factors - such as the Glorious Revolution's strengthening of property rights emphasized by North and Thomas (1973) facilitated the acceleration of actual growth compared to the predicted rate. If chance played a role in the absolute rate of progress after 1700, it is natural to ask if it also played a role in determining which country got to be the First Industrial Nation. This is what we examine next.

44 The explanation is provided by Eqs. (14 ) and (15). Initially, capital accumulation proceeds slowly, such that $\gamma_{K}$ is small and $\gamma_{T, M}<\gamma_{T, A}$. Thus, the relative price of manufacturing increases. In later periods, when $\gamma_{K}$ is larger, the opposite is true.

45 Although investment rates are lower in later periods, the virtuous capital-externality-circle initiated in the early periods prevails.

46 The model is solved numerically as described in Appendix A.6. For the stochastic simulations, we allow agricultural TFP $A_{A}$ to follow the random process described in Section 3.2.1.

Springer 

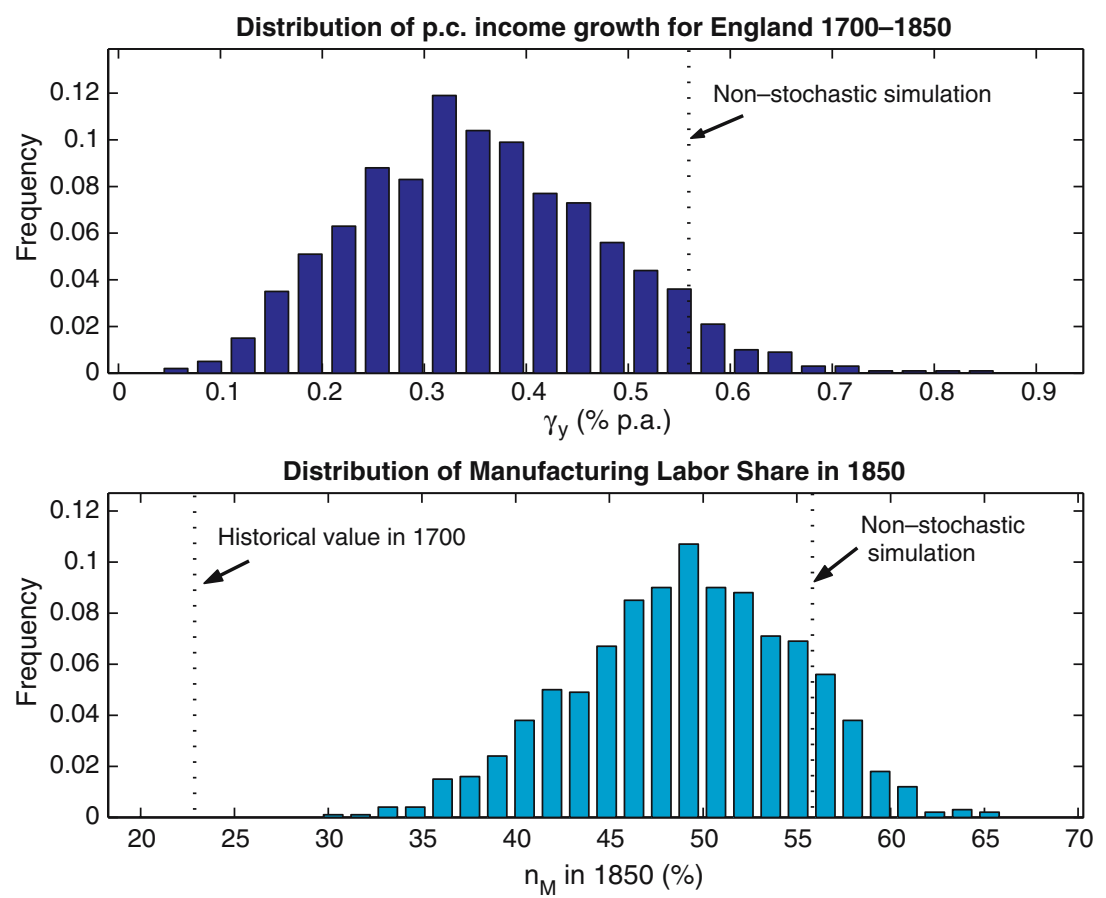

Fig. 6 Stochastic simulation for England 1700-1850

\subsection{Probabilities of industrialization in other countries}

Why did England industrialize first? Could it have been France or China instead? In our model, industrialization occurs stochastically, but initial income, inequality, and the demographic regime are crucial determinants. Starting positions differed a good deal. We summarize some key variables in Table 5. England was both richer and more urbanized than France and China in 1700.

Table 5 Income, urbanization and population growth in other countries

\begin{tabular}{|c|c|c|c|c|c|c|c|}
\hline \multirow[t]{2}{*}{ Year } & \multicolumn{2}{|c|}{$\begin{array}{l}\text { p.c. income* } \\
\text { (in } 1990 \text { Geary- } \\
\text { Khamis dollars) }\end{array}$} & \multicolumn{2}{|l|}{$\begin{array}{l}\text { Population } \\
\text { growth } \\
\text { (\% p.a.) }\end{array}$} & \multicolumn{2}{|c|}{$\begin{array}{l}\text { Urban Shares } \\
(\%)\end{array}$} & \multirow{2}{*}{$\begin{array}{l}N_{M} / N^{* *} \\
(\%) \\
1700\end{array}$} \\
\hline & 1700 & 1820 & $1700-1820$ & $1820-1850$ & 1700 & 1800 & \\
\hline England & 1250 & 1706 & $0.76^{* * *}$ & 0.83 & 13.3 & 20.3 & 23 \\
\hline France & 910 & 1135 & 0.31 & 0.51 & 9.2 & 8.8 & 16 \\
\hline China & 600 & 600 & 0.85 & 0.26 & 6.0 & 3.8 & 10 \\
\hline
\end{tabular}

Sources: Maddison (2003) for p.c. income and population growth; de Vries (1984) for urban shares in England and France; Broadberry and Gupta (2005a) for urban shares in China

* Maddison figures are controversial. In the calibration we rely on urban share

** Manufacturing Labor Share. For England: Calculated from Crafts (1985), leaving out services. For France and China: Author's calculation based on urban shares, assuming that the British ratio of the urban share to total employment in manufacturing is indicative of ratios elsewhere

*** 1701-1751: 0.25\%, from Wrigley and Schofield (1981) 
Table 6 Calibration of initial conditions in cross-country simulations

\begin{tabular}{lllll}
\hline & $\frac{N_{M}}{N}$ & $\gamma_{b}$ & $\gamma_{N}$ & $\underline{c}$ \\
\hline England & $23 \%$ & $0.29 \%$ & $0.28 \%$ & 1.101 \\
France & $16 \%$ & $0.32 \%$ & $0.32 \%$ & 1.045 \\
China & $11 \%$ & $4.0 \%$ & $0.73 \%$ & 0.969 \\
\hline
\end{tabular}

In order to compare England's chances of industrialization in 1700 with those of other countries, we need detailed, reliable data on per capita incomes, birth rates, and income support. There has recently been an upsurge of historical research on Chinese wages and the productivity of its agricultural sector. Revisionists' arguments along the lines of Pomeranz (2000) have proven to be overoptimistic about living standards in China. Land productivity was impressive, especially in the Yangtze delta. In some parts, where political pressures limited rent increases, peasants could live quite well, especially when measured in terms of the price of agricultural goods. Where silver wages are used - more relevant for our comparisons of the ability to purchase goods other than food - the gap between Europe and China is wide (Broadberry and Gupta, 2005a). Without politically skewed incomes, however, conditions were much less favorable. Laborers were paid poorly. Everywhere after 1620, as a result of population pressure, "the downward trend toward immiseration is stark" (Allen, 2006). ${ }^{47}$ In the most comprehensive study of comparative living standards yet, Allen Bassino, Ma, Mall-Murata, and van Zanden (2005) found that Chinese families' incomes lagged behind Northern European ones by a large margin. Only in the impoverished South of Europe - like Milan - were living standard comparable. Allen et al. (2005) suggest that the ratio of English to Chinese wages may have been close to 2:1. Broadberry and Gupta (2005a) derive even more pessimistic figures for silver wages in the Yangtze.

In order to stack the odds in favor of China's prospects, we consistently make the most optimistic assumptions possible. To capture the much more prosperous conditions in the most advanced areas (Allen et al., 2005), like the Yangtze delta, we do not rely on the Maddison income figures. Instead, we calibrate with the urban shares from Broadberry and Gupta (2005a), which imply a relatively smaller gap in incomes. Table 6 gives our calibration figures. We calibrate TFP in agriculture and manufacturing such that we match both net population growth and manufacturing labor shares as close as possible. ${ }^{48}$ Given the calibrated TFP, we can compute the implied consumption level relative to subsistence, $c / \underline{c}$. As Allen et al. (2005) argue, there is indeed a substantial part of the population in China that is not able to satisfy basic subsistence needs, as reflected by $c / \underline{c}<1$. As given in Eq. (12), this corresponds to starvation of part of the population such that $\gamma_{N}<\gamma_{b}$. In France, on the other hand, $c>\underline{c}$ such that everyone survives and $\gamma_{N}=\gamma_{b}$. Note that since we avoided the pitfalls of size effects, TFP growth in our model is not dependent on size of the economy as such, but is driven by capital accumulation. More capital in agriculture yields the same benefits as in manufacturing. This biases our results towards industrialization in China, since there almost all capital is used in agriculture in 1700.

\footnotetext{
47 Allen (2005a) does not provide figures for 1700, offering estimates for 1620 instead. His finding of a strong trend towards immiseration, and of broady comparable starting levels in incomes sustained by politically biased distribution of rents, is consistent with our argument here.

48 Deviations from historical population growth and manufacturing labor shares as given in Table 5 are small. As in the English case, manufacturing TFP is chosen such that $p_{M}=2$. 
The birth rates for both France and China are constant. In the case of France, this is a simplification - population growth was low, and birth rates declined after 1800 in parallel with death rates. Wrigley and Schofield (1981) show that France had more of a "high pressure" demographic regime, with birth rates responding too little to avoid additional adjustment through the positive check. We deliberately simplify to highlight the importance of the demographic regime, and assume a constant birth rate to match observed population growth rates. For China, we also use historical data on population growth. We observe maximum fertility rates in the period immediately before the demographic transition in China (Chesnais, 1992), which implies net birth rates of $4 \%$ in our setup (with infinitely-lived agents). Analogous to the British case, French shocks are derived from the movement of grain wages (Labrousse, Romano, $\&$ Dreyfus, 1970). ${ }^{49}$ For China, we used both the French and the British shock parameters in the stochastic simulation, but the results do not differ. According to our assumptions in section 3.4.3, there is also no redistribution to support lower incomes during times of crisis in France and China. ${ }^{50}$

For China, our simulations on average predict a decline in per capita income, combined with a very low labor share in manufacturing. ${ }^{51}$ There are some cases of industrial development, but they are rare and stop far short of the extent of industrialization witnessed in England. The periods of benign development result from a sequence of positive shocks, which leads to capital accumulation outpacing demographic growth. As aggregate capital grows, the externality pushes up TFP. Eventually, the investment schedule crosses the line defined by $\delta+\gamma_{N}$ twice: from below for lower $k$ and from above for higher $k$ (due to decreasing returns to capital the investment schedule eventually becomes downward-sloping). The latter is a stable equilibrium with growing population and p.c. income (Right panel of Fig. 2).

France has markedly higher probabilities of industrializing than China. Its average share of the labor force in manufacturing in our simulations is $36.5 \%-$ much less than Britain, but a long way away from pre-industrial stagnation. Growth is markedly slower, at less than half the British rate. The two distributions overlap to some extent. As Crafts (1977) argued, much of the difference between the experience of France versus England could be due to chance. Detailed examinations of "France's failure" may have suffered from hindsight bias, finding causes where there was simply bad luck. In comparison with China, on the other hand, chance plays almost no role - the British performance in all of our simulations is markedly better than the best possible one for China.

\subsection{Turning England into China}

What was crucial about England's starting conditions - its demographic regime, its favorable income level, or the redistributive institutions that raised incomes for the bottom $40 \%$ of the population?

First, we simulate the development of the British economy using the same parameters as in the baseline calibration before, but changing the birth rate to a constant $4 \%$. In the majority of simulations, after introducing the Chinese demographic regime in England, individual consumption declines to subsistence, so that all consumption

49 We use figures for 1726-1792 and find $\theta=0.595(t=5.71)$ and $\sigma_{\varepsilon}=0.13$.

50 As in the case of England, the effect of redistribution is negligible.

51 This is in line with the tendency towards involution found by Allen (2005a). 

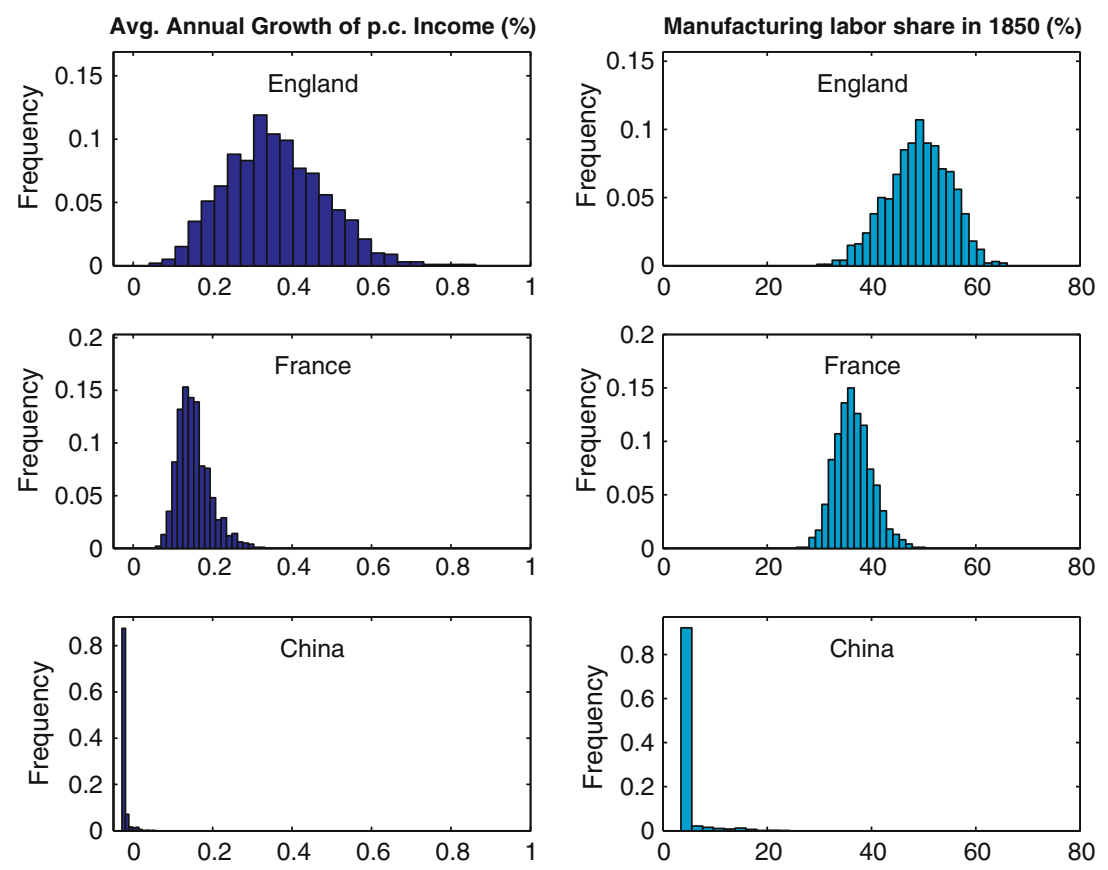

Fig. 7 Stochastic simulation for 1700-1850

expenditure goes to agriculture. The economy typically starts near point C (Fig. 2). Population grows very quickly because higher initial incomes reduce death rates. Despite high savings rates, capital per head declines. This pushes the economy towards A. Instead of growing by $0.34 \%$ on average per year, per capita incomes now fall by $0.15 \%$ annually. As a result of high birth rates, $N$ can grow quite quickly in a short period of time. Eventually, the economy reaches a stable equilibrium at point A, where during periods with average productivity, the only demand for manufactured goods comes from investment. Over the period as a whole, demographic growth will be slower than in the baseline case due to high mortality, driven by falling living standards. Our results therefore suggest that, instead of being able to industrialize, England would have seen an economic collapse with a high-pressure demographic regime. This underlines the crucial importance of fertility limitation as part of Europe's unique demographic regime. In passing, we might want to note that the parts of Europe where the European Marriage Pattern was weakest (Southern and Eastern Europe (Hajnal, 1965) also suffered from long delays before industrial development got under way. ${ }^{52}$

What is the importance of starting conditions? Is a high starting point crucial for England's high chance to industrialize? We can repeat the simulations with Chinese starting conditions, but an English demographic regime. In Fig. 2 (left panel), the inv / $k$ curve is shifted down and to the right. The economy at B will now grow more slowly as aggregate capital accumulation slows to a crawl. As Table 7 shows, with Chinese

\footnotetext{
52 Japan is also a case in point for our model - as noted by Mosk (1976), it had strikingly low fertility during the Tokugawa period. Infanticide, not fertility limitation through changes in nuptiality, may have been decisive.
} 
Table 7 Counterfactual simulations for Britain results for 1850

Note: All results are the median of 1000 stochastic simulations, each over 150 periods

\begin{tabular}{|c|c|c|c|}
\hline & $\begin{array}{l}\text { p.c. Income } \\
\text { growth }\end{array}$ & $\begin{array}{l}\text { Population } \\
\text { growth }\end{array}$ & $\begin{array}{l}\text { Labor } \\
\text { share in } \mathrm{M}\end{array}$ \\
\hline Baseline Model & $0.34 \%$ & $0.57 \%$ & $49.1 \%$ \\
\hline $\begin{array}{l}\text { Chinese Demography } \\
\text { Chinese Starting }\end{array}$ & $-0.15 \%$ & $0.12 \%$ & $4.6 \%$ \\
\hline $\begin{array}{l}\text { Levels } \\
\text { No Subsidies }\end{array}$ & $0.13 \%$ & $-0.08 \%$ & $28.2 \%$ \\
\hline to the Poor & $0.33 \%$ & $0.56 \%$ & $48.4 \%$ \\
\hline
\end{tabular}

starting levels and the English demographic regime, the country would have seen slow growth of per capita incomes. The share of the population in manufacturing rises gradually, eventually surpassing England's level in 1700. Population may stagnate or even fall because initially, many households are near the subsistence minimum. ${ }^{53}$

For our final counterfactual, we examine the effects of redistribution. In our model, the Poor Law is potentially important because it ensures that the malnourished can work even during years with poor harvests. We model this by assuming that in the absence of redistribution, during crisis periods $(c<\underline{c})$ the part of the population that will starve also does not work (reflecting the basic insight from Fogel, 1994). Adding this effect to our simulations amplifies the impact of negative shocks in the short run. Over the long run, it hardly matters at all because higher land-labor ratios have a stabilizing influence. In China, the absence of redistribution makes catastrophic declines of population and output more likely. As noted by Lagerlöf (2006), these are a constant feature of the pre-industrial world. As it happens, British per capita incomes are too high even in 1700 for this mechanism to make much of a difference. Very good outcomes - showing growth above $0.6 \%$ p.a. - are more common in the simulations with redistribution, but the average is basically the same for stochastic simulations with and without the Poor Law.

\section{Conclusions}

This paper offers quantitative answers to our two initial questions: "Why England?" and "why Europe?" Based on a calibrated two-sector growth model with an aggregate capital externality, we argue that Europe's unique demographic regime ensured starting positions that made industrial development much more likely. No lucky accident through a few good harvests, or as a result of natural resource endowments, could have similarly raised the chances to industrialize. Nor could redistribution, on its own, have had sufficiently benign effects.

We derive a model that focuses on the first transition in unified growth theory - from Malthusian stagnation to a post-Malthusian regime (Galor \& Weil, 2000; Galor, 2005). The key driving variable is not the generation of ideas through a link with population size or an increase in the population's quality. Factors highlighted by historians of technology play a crucial role - such as the importance of chance in new inventions, the role of tinkering, and essentially non-economic motives for innovation (Mokyr, 1990). All of this suggests that the biggest single determinant of

53 Because of low fertility in the English demographic regime, recovery from negative shocks takes a long time. 
technological progress was not the patent system, nor population size, but the fertility regime and the use of differentiated capital inputs. Interacting with the installed stock of machinery created the opportunities for "microinventions," in Mokyr's phrase.

England's chances to make many microinventions were good mainly because of high per capita incomes, resulting from fertility restriction. A more effective work force because of redistributive institutions raised output and increased industrialization probabilities, but this channel's role was small. These conclusions follow from our simulations of England's Industrial Revolution, which show a close fit between historical fact and model output. We also show how important it was that population growth accelerated in a context of high per capita incomes. Economic historians have long puzzled over the fact that the country with the biggest population increase between 1550 and 1800 also saw the biggest increase in per capita output (Wrigley, 1988). In our model, this is no accident, but arises naturally from the interaction of starting conditions, the demographic regime, and the capital-use externality.

Based on the simulation for England, we vary the parameter values to examine France's and China's chance to develop. The exercise suggests that France had reasonable prospects to develop, too. The absence of the Poor Law and a more high-pressure demographic regime reduced its chances, but not to such an extent that history could not have played itself out differently. The answer for China is fundamentally different. Because of the capital-diluting effects of rapid population growth, its chances of industrializing were very small. Only very unlikely sequences of good shocks could have given it a chance to develop.

Our results also highlight one mechanism through which inequality in the early stages of development may be growth-reducing - if nutrient availability overall is low, redistribution from top to bottom may create opportunities for growth because it raises the workforce's effectiveness. This could qualify the conclusions by Galor and Moav (2004). They argued that greater inequality is beneficial when physical capital accumulation is key. The Galor and Moav effect may be conditional on overall nutrient supply being sufficiently generous to leave all groups of society in a position to perform hard labor. In our simulations, however, the consequences of workforce effectiveness matter, but are never large enough in the long run to dominate our results.

Economic historians have sometimes been sceptical that endogenous growth models can capture the complexity of the historical industrialization experience. Standard modelling approaches grappled with cross-sectional differences in timing and speed. Crafts (1995) concluded that the contrasting experiences of France and England did not seem to fit the mould of early models. Because of this, he argued interpretations based on exogenous growth should be preferred. Our results demonstrate that more recent advances in unified growth theory can do much to resolve seeming contradictions between the historical record and growth models. In particular, the emphasis on capital accumulation and declining constraints on population growth during the first transition from stagnation to the post-Malthusian state prove useful. In this way, rigorous, quantitative examinations of the cross-sectional differences in the industrialization process can yield important conclusions about the nature of early development.

Acknowledgements We would like to thank seminar audiences at the LSE, IIES Stockholm, UPF Barcelona, at the CEPR-ESF Conference 'The long run growth and development of the world economy' in Venice, May 2005, and at the 2006 EEA meetings in Vienna for useful suggestions. Bob 
Allen, Steve Broadberry, Fernando Bronner, Antonio Ciccone, N.F.R. Crafts, Ron Findlay, Alexander Ludwig, Joel Mokyr, Patrick O'Brien, Torsten Persson, Diego Puga, Albrecht Ritschl, Sevi Rodriguez-Mora, Peter Temin, Jaume Ventura, Fabrizio Zilibotti kindly offered advice. We also owe a special debt to Oded Galor and two anonymous referees. Financial support by the Centre for International Economics at UPF (CREI) and CREA (Barcelona) is gratefully acknowledged.

\section{Appendix}

Appendix A.1 - Optimization of production

In this section of the appendix we derive the first order conditions (FOC) for profitmaximization of the production side of the model and calculate the demand function for capital varieties.

Final sector firms take input and output prices as given. A unit of capital variety $j$ has value $p(j)$ and is borrowed at the gross interest rate $R_{K}$. Labor and land are paid wage $w$ and land rental rate $r_{L}$, respectively. Final producers solve the following problems in agriculture and manufacturing production:

$$
\begin{aligned}
& \max \left\{Y_{A}-\int_{0}^{J} R_{K} p(j) v_{A}(j) d j-w N_{A}-r_{L} L\right\} \\
& \max \left\{p_{M} Y_{M}-\int_{0}^{J} R_{K} p(j) v_{M}(j) d j-w N_{M}\right\}
\end{aligned}
$$

subject to the production functions (6) and (7). Capital producing firms take input prices as given but set the price of their own output in order to maximize profits. For given input prices, they solve the cost minimization problem

$$
\min \left\{\int_{0}^{J} R_{K} p(j) v_{\widetilde{J}}(j) d j+w N_{\widetilde{\jmath}}-\lambda_{\widetilde{\jmath}}[v(\widetilde{\jmath})-\bar{v}(\widetilde{\jmath})]\right\}
$$

subject to the production function (8), where $\bar{v}(\widetilde{J})$ is the targeted production amount of variety $\widetilde{\jmath}$ and $\lambda_{\tilde{\jmath}}$ is a Lagrange multiplier. In the following we derive the first order conditions for problems (16) - (18) and use them to obtain the demand function for capital varieties.

For agricultural output, Eq. (16) has the FOC

$$
\begin{aligned}
R_{K} p(j) & =\phi v_{A}(j)^{-\frac{\epsilon}{1+\epsilon}} A_{A}\left[\int_{0}^{J} v_{A}(j)^{\frac{1}{1+\epsilon}} d j\right]^{\phi(1+\epsilon)-1} N_{A}^{\mu} L^{1-\phi-\mu}, \quad \forall j \\
w & =\mu A_{A}\left[\int_{0}^{J} v_{A}(j)^{\frac{1}{1+\epsilon}} d j\right]^{\phi(1+\epsilon)} N_{A}^{\mu-1} L^{1-\phi-\mu} \\
r_{L} & =(1-\phi-\mu) A_{A}\left[\int_{0}^{J} v_{A}(j)^{\frac{1}{1+\epsilon}} d j\right]^{\phi(1+\epsilon)} N_{A}^{\mu} L^{-\phi-\mu}
\end{aligned}
$$


The corresponding FOC for manufacturing production follow from (17)

$$
\begin{aligned}
R_{K} p(j) & =\eta v_{M}(j)^{-\frac{\epsilon}{1+\epsilon}} p_{M} A_{M}\left[\int_{0}^{J} v_{M}(j)^{\frac{1}{1+\epsilon}} d j\right]^{\eta(1+\epsilon)-1} N_{M}^{1-\eta}, \quad \forall j \\
w & =(1-\eta) p_{M} A_{M}\left[\int_{0}^{J} v_{M}(j)^{\frac{1}{1+\epsilon}} d j\right]^{\eta(1+\epsilon)} N_{M}^{-\eta}
\end{aligned}
$$

Finally, the cost-minimization problem (18) of a capital variety producer $\tilde{J}$ implies

$$
\begin{aligned}
R_{K} p(j) & =\eta v_{\widetilde{J}}(j)^{-\frac{\epsilon}{1+\epsilon}} \lambda_{\widetilde{J}} A_{\widetilde{J}}\left[\int_{0}^{J} v_{\widetilde{J}}(j)^{\frac{1}{1+\epsilon}} d j\right]^{\eta(1+\epsilon)-1} N_{\widetilde{J}}^{1-\eta}, \quad \forall j \\
w & =(1-\eta) \lambda_{\widetilde{J}} A_{\widetilde{J}}\left[\int_{0}^{J} v_{\widetilde{J}}(j)^{\frac{1}{1+\epsilon}} d j\right]^{\eta(1+\epsilon)} N_{\widetilde{J}}^{-\eta}
\end{aligned}
$$

Note that we have not imposed symmetry of capital variety prices in any of these derivatives. Rather, we will obtain symmetry in the following steps, which lead to the demand function for capital varieties. Equations (24) and (25) can be used to derive

$$
v_{\widetilde{J}}(j)^{\frac{1}{1+\epsilon}}=\left[\frac{w}{1-\eta} \frac{\eta}{R_{K}} \frac{1}{\int_{0}^{J} v_{\widetilde{J}}(j)^{\frac{1}{1+\epsilon}} d j} N_{\widetilde{J}} \frac{1}{p(j)}\right]^{\frac{1}{\epsilon}}
$$

Integrating over all varieties $j \in[0, J]$ yields

$$
\left[\int_{0}^{J} v_{\widetilde{J}}(j)^{\frac{1}{1+\epsilon}} d j\right]^{1+\epsilon}=\frac{w}{1-\eta} \frac{\eta}{R_{K} P_{J}} N_{\widetilde{J}}
$$

where $P_{J}$ is the price index of existing capital varieties $j \in[0, J]$, given by

$$
P_{J} \equiv\left[\int_{0}^{J} p(j)^{-\frac{1}{\epsilon}} d j\right]^{-\epsilon}
$$

We will need labor demand $N_{\widetilde{J}}$ as a function of a given amount of output of variety $\widetilde{J}, \bar{v}_{\tilde{J}}$, later on. To obtain this we plug (27) into the production function (8), which gives $^{54}$

$$
N_{\widetilde{\jmath}}=\frac{1-\eta}{w} \frac{1}{A_{\widetilde{J}}}\left(\frac{R_{K} P_{J}}{\eta}\right)^{\eta}\left(\frac{w}{1-\eta}\right)^{1-\eta}\left(\bar{v}_{\tilde{\jmath}}+F\right)
$$

We then derive the demand for an existing variety $j$ by a producer of a new variety $\tilde{j}$ by plugging (27) into (26) and substituting $N_{\widetilde{J}}$ from (29)

$$
\nu_{\widetilde{J}}(j)=\frac{\eta}{R_{K} P_{J}}\left[\frac{P_{J}}{p(j)}\right]^{\frac{1+\epsilon}{\epsilon}} \frac{1}{A_{\widetilde{J}}}\left(\frac{R_{K} P_{J}}{\eta}\right)^{\eta}\left(\frac{w}{1-\eta}\right)^{1-\eta}\left(\bar{v}_{\widetilde{J}}+F\right)
$$

Demand for variety $j$ by a producer of a new variety depends on the price of $j$ relative to the aggregate price index of capital varieties $P_{J}$. Note that $\bar{\nu}_{\widetilde{J}}$ denotes the amount of

54 In this step we implicity impose that the constraint in (18) holds with equality, i.e., production is at its efficiency frontier. 
the new variety $\widetilde{\jmath}$ that is actually produced, whereas $v_{\tilde{J}}(j)$ is the amount of an existing variety $j$ used in the corresponding production process. We can now derive the total cost of producing $\bar{v}_{\tilde{J}}$ from (28) to (30):

$$
C_{\widetilde{J}}=\int_{0}^{J} R_{K} p(j) v_{\widetilde{J}}(j) d j+w N_{\widetilde{J}}=\frac{1}{A_{\widetilde{J}}}\left(\frac{R_{K} P_{J}}{\eta}\right)^{\eta}\left(\frac{w}{1-\eta}\right)^{1-\eta}\left(\bar{v}_{\tilde{J}}+F\right)
$$

Consequently, the marginal cost of variety $\widetilde{\jmath}$ production is given by

$$
M C_{\widetilde{J}}=\frac{1}{A_{\widetilde{J}}}\left(\frac{R_{K} P_{J}}{\eta}\right)^{\eta}\left(\frac{w}{1-\eta}\right)^{1-\eta} \equiv M C_{\widetilde{J}}, \quad \forall \widetilde{J}
$$

Marginal costs are the same for all capital variety producers $\widetilde{J}$, which is one of the steps in our derivation of the symmetric equilibrium. We need two more ingredients to derive total demand for variety $j, v^{d}(j)$ : the demand for $j$ by agricultural and by manufacturing production. Using the FOC (19) - (23) and the production functions (6) and (7) we repeat the steps outlined in (26) - (30) and obtain

$$
\begin{aligned}
& v_{A}(j)=\frac{\phi}{R_{K} P_{J}}\left[\frac{P_{J}}{p(j)}\right]^{\frac{1+\epsilon}{\epsilon}} \frac{1}{A_{A}}\left(\frac{R_{K} P_{J}}{\phi}\right)^{\phi}\left(\frac{w}{\mu}\right)^{\mu}\left(\frac{r_{L}}{1-\phi-\mu}\right)^{1-\phi-\mu} Y_{A} \\
& v_{M}(j)=\frac{\eta}{R_{K} P_{J}}\left[\frac{P_{J}}{p(j)}\right]^{\frac{1+\epsilon}{\epsilon}} \frac{1}{A_{M}}\left(\frac{R_{K} P_{J}}{\eta}\right)^{\eta}\left(\frac{w}{1-\eta}\right)^{1-\eta} Y_{M}
\end{aligned}
$$

Total demand for an existing intermediate variety $j$ can be derived from (30), (33), and (34):

$$
v^{d}(j)=\left[\frac{P_{J}}{p(j)}\right]^{\frac{1+\epsilon}{\epsilon}} \Phi
$$

where

$$
\begin{aligned}
\Phi \equiv & \int_{0}^{1} \frac{\phi}{R_{K} P_{J}} \frac{1}{A_{A}}\left(\frac{R_{K} P_{J}}{\phi}\right)^{\phi}\left(\frac{w}{\mu}\right)^{\mu}\left(\frac{r_{L}}{1-\phi-\mu}\right)^{1-\phi-\mu} Y_{A}(i) d i+\ldots \\
& \ldots \int_{0}^{1} \frac{\eta}{R_{K} P_{J}} \frac{1}{A_{M}}\left(\frac{R_{K} P_{J}}{\eta}\right)^{\eta}\left(\frac{w}{1-\eta}\right)^{1-\eta} Y_{M}(i) d i+\ldots \\
& \ldots \int_{0}^{\widetilde{J}} \frac{\eta}{R_{K} P_{J}} \frac{1}{A_{\widetilde{J}}}\left(\frac{R_{K} P_{J}}{\eta}\right)^{\eta}\left(\frac{w}{1-\eta}\right)^{1-\eta}\left(\bar{v}_{\tilde{J}}+F\right) d \widetilde{\jmath}
\end{aligned}
$$

The first two rows in (36) represent total demand for variety $j$ from final producers $i \in[0,1]$ (i.e., from agriculture and manufacturing), and the last row is demand from currently active new variety producers $\widetilde{J} \in[0, \widetilde{J}]$. Note that the price of variety $j$ enters $\Phi$ only through the aggregate price index $P_{J}$, so that its effect on $\Phi$ is negligible. Consequently, $\Phi$ is treated as a constant in a capital variety producer's profit maximizing price decision:

$$
\max _{p_{\widetilde{J}}}\left\{p_{\widetilde{J}} v^{d}\left(p_{\widetilde{J}}\right)-C_{\widetilde{J}}\left(v^{d}\left(p_{\widetilde{J}}\right)\right)\right\}
$$

where $v^{d}\left(p_{\widetilde{J}}\right)$ is the total demand for the new capital variety $\widetilde{\jmath}$. Using (31), (32), and (35), we obtain the profit-maximizing price as a markup over marginal cost of production $M C_{\widetilde{J}}$, which is the same for each capital variety producer, so that the price of all newly produced capital varieties in a given period is the same: 


$$
p_{\widetilde{J}}=(1+\epsilon) M C_{\widetilde{J}} \equiv p_{\widetilde{J}}, \quad \forall \widetilde{J}
$$

Free entry into the capital producing sector implies that each firm $\tilde{\jmath}$ makes zero profits, i.e., (37) is zero. This, together with the optimal price $p_{\widetilde{J}}$ from (38) implies

$$
v(\widetilde{\jmath})=\frac{F}{\epsilon}, \quad \forall \widetilde{\jmath}
$$

That is, the amount of each newly produced capital variety, $v(\widetilde{J})$, is the same in a given period, and moreover, is constant over time, even if factor prices and thus marginal costs change.

Appendix A.2 - Capital varieties and aggregate capital

In the following, we refer to aggregate capital as the collection of all machines available for production in a given period:

$$
K=\int_{0}^{J} v(j) \mathrm{d} j
$$

where $v(j)$ is the amount of capital variety $j$ when it was produced $(v(j)$ does not change until $j$ depreciates - it then becomes zero). We choose the fixed cost $F$ such that $F=\epsilon$. Equation (39), and the fact that $v(j)$ is constant, imply:

$$
v(\widetilde{\jmath})=v(j)=1, \quad \forall \widetilde{\jmath}, j
$$

Therefore, the amount of each capital variety circulating in the economy (new and existing ones) is the same. Our choice of $F$ serves to simplify the following analysis since it implies, together with (40), that

$$
J=K
$$

that is, the total amount of capital in the economy is equal to the number of capital varieties. Moreover, newly produced capital is given by $\int_{0}^{\widetilde{J}} v(\widetilde{J}) \mathrm{d} \widetilde{J}=\widetilde{J}$. Consequently, $\widetilde{J}_{t}$ denotes the mass of capital variety producers as well as the number of varieties that are produced in period $t$ (but are used for production only from the next period on). The law of motion for the aggregate capital stock is thus equivalent to the one for varieties, $J_{t+1}=(1-\delta) J_{t}+\widetilde{J}_{t}$. The mass of currently active capital variety producers can be derived from total investment, $I=Y-e N$ :

$$
\widetilde{J}_{t}=\frac{I_{t}}{p_{\widetilde{J}, t}}=J_{t+1}-(1-\delta) J_{t}
$$

According to Eq. (38), the price of all newly produced capital varieties could differ from old varieties if marginal costs vary. We therefore add the assumption that owners of existing capital varieties exert the same market power as producers of new ones. All capital of variety $j$ is owned by one individual or entity (although, of course, different entities can own different varieties). ${ }^{55}$ The owner of an existing variety $j$ chooses $p_{j}$ to maximize $p_{j} v^{d}\left(p_{j}\right)$ subject to $v^{d} \leq 1$, since the amount owned of each $j$ is one. Equation

\footnotetext{
55 We noted before that existing capital varieties $j \in[0, J]$ are owned by consumers. Our assumption thus requires that population $N$ be a multiple of the measure of capital varieties $J$. To circumvent this problem we can assume that single consumers bring their money to banks and that these act as profit-maximizing owners of each capital variety.
} 
(35) with $\epsilon>0$ implies that revenue $p_{j} v^{d}\left(p_{j}\right)$ is decreasing in the price of $j$. Therefore, owners of existing varieties want to charge the smallest possible price at which the constraint $v^{d} \leq 1$ holds. The constraint holds with equality if $p_{j}=p_{\widetilde{J}}$. Intuitively, if the owner of an existing capital variety chooses a price above $p_{\widetilde{J}}$, demand is lower than unity and part of the variety is wasted. This is not optimal because a marginal price decrease would raise the revenue and thus profits. On the other hand, if $p_{j}<p_{\widetilde{J}}$, demand is larger than unity and the fixed supply of one unit is not sufficient to satisfy demand. Thus, the price of existing and new capital varieties is the same within each period. We can now define the price of capital $p_{K}$ :

$$
p(\widetilde{\jmath})=p(j) \equiv p_{K}, \quad \forall \widetilde{\jmath}, j
$$

Equation (41) establishes symmetry in capital producing sectors. In the following we slightly abuse notation and use $\widetilde{J}$ as the subscript for a representative new capital producer as well as for the mass of all producers of new capital varieties. Because the mass of final sector firms is one, output $\left(Y_{A}, Y_{M}\right)$ and factor inputs $\left(N_{i}, L\right.$, and $v_{i}(j)$ for $i=A, M)$ of a representative final producer are equal to aggregate final output and inputs. The price equality of capital varieties $j$ given in Eq. (44), used in (30), (33), and (34), implies that firms use the same amount of each variety, i.e., $v_{i}(j)=v_{i}, \quad \forall j$ and $i=A, M, \widetilde{J}$. Clearly, the total amount demanded of each variety (i.e., the integral of $v_{i}(j)$ over all producers $i$ ) is also equal for all $j: v(j)=v$. Market clearing of each existing variety $j$ then requires ${ }^{56}$

$$
v_{A}+v_{M}+\widetilde{J} v_{J}=v=1
$$

where the last equality follows from (41). At the aggregate level all capital, labor, and land are used in each period. Integrating (45) over all existing varieties $j \in[0, J]$ yields

$$
J v_{A}+J v_{M}+\widetilde{J} v_{\widetilde{J}}=J v=J=K
$$

Recalling that $J=K$, we can interpret $v_{A}, v_{M}$, and $\widetilde{J} v_{\widetilde{J}}$ as the aggregate capital shares in agriculture, manufacturing and variety production, respectively.

Appendix A.3 - Market clearing and equilibrium

The market clearing conditions for single capital varieties and aggregate capital are given by (45) and (46), respectively. The corresponding conditions for labor and land are:

$$
\begin{array}{r}
N_{A}+N_{M}+\widetilde{J} N_{\widetilde{J}}=N \\
\int_{0}^{1} L d i=L
\end{array}
$$

where the latter condition is trivial because land is only used for agriculture by the $[0,1]$ final sector firms. Market clearing in final product markets requires:

$$
\begin{aligned}
N c_{A} & =Y_{A} \\
N c_{M} & =Y_{M}
\end{aligned}
$$

56 Recall that newly produced varieties are only used from the next period on, but existing varieties are used by the mass $J$ of new varieties producers. 
Before defining the equilibrium, we need to introduce total nominal output $Y$, since this is the basis for individual income $y=Y / N$ that enters in consumers' intertemporal optimization decision. Let

$$
Y=Y_{A}+p_{M} Y_{M}+p_{K} \widetilde{J}
$$

where the last term represents the total value of newly produced capital varieties $(\widetilde{J} v$, with $v=1$ ). This equation, together with (43), $J=K$, and the condition that consumers' budget constraints hold with equality $\left(Y_{A}+p_{M} Y_{M}=e N\right)$, implies the law of motion for capital

$$
K_{t+1}=(1-\delta) K_{t}+\left(1 / p_{K, t}\right)\left(Y_{t}-e_{t} N_{t}\right)
$$

that is taken into account in the intertemporal optimization (4) by households. ${ }^{57}$

Definition 1 Given initial values $A_{A, 0}, N_{0}, K_{0}=\int_{0}^{J_{0}} v_{0}(j) d j=J_{0}\left(\right.$ since $\left.\nu_{0}(j)=1\right)$, and $L$, a competitive equilibrium consists of sequences for $t \geq 0$ of agricultural TFP, $\left\{A_{A, t}\right\}$; prices, $\left\{p_{M, t}, p_{K, t}, R_{K, t}, r_{L, t}, w_{t}\right\}$; final sector firm allocations $\left\{Y_{A, t}, Y_{M, t}, v_{A, t}, v_{M, t}\right.$, $\left.N_{A, t}, N_{M, t}, L_{t}\right\}$, capital sector firm allocations $\left\{v_{t}, N_{\widetilde{J}, t}, v_{\widetilde{J}, t}\right\}$ for all $\widetilde{J} \in\left[0, \widetilde{J}_{t}\right]$ producing at $t$; and household allocations $\left\{c_{A, t}, c_{M, t}\right\}$ such that (i) Given the sequence of prices, final sector firm allocations solve the problems specified in (16) and (17), and capital sector firm allocations solve (18); (ii) Producers of new capital varieties charge the profit-maximizing price given by (38), and, due to free entry, sell the amount given in (39) of each variety; (iii) Owners of existing capital varieties charge the price given by (44); (iv) Given the sequence of prices, consumer allocations maximize (1) subject to $c_{A, t}+p_{M, t} c_{M, t} \leq e_{t}$, and consumer consumption expenditures $e_{t}$ satisfy the Euler equation (5); (v) The market clearing conditions (45)-(50) hold; (vi) The law of motion of capital is given by (52); and (vii) Population growth follows (11)-(13).

\section{Appendix A.4 - Aggregate externality representation}

In this section we utilize the symmetry of capital variety use in production to derive a simplified representation of the model. It offers two advantages: First, the influence of aggregate externalities on productivity can easily be represented in the production functions. Second, with a single assumption about TFP in capital variety production, we simplify the model such that variety production can be included in the manufacturing sector. This reduces the number of equations that must be simulated to solve the model numerically.

Using $v_{i}(j)=v_{i}, \forall j$ and $i=A, M, \widetilde{J}$ in the production functions (6), (7), and (8), the integral over all capital varieties $j \in[0, J]$ simplifies to $J^{\phi \epsilon}\left(J v_{A}\right)^{\phi}$ in agriculture, $J^{\eta \epsilon}\left(J v_{M}\right)^{\eta}$ in manufacturing, and $J^{\eta \epsilon}\left(J v_{\widetilde{J}}\right)^{\eta}$ in capital variety production. The terms in parentheses $\left(J v_{i}\right)$ represent the total capital used in firm $i$ (i.e., the number of capital varieties multiplied by the amount utilized of each variety). It is convenient to simplify notation and label these terms $K_{A} \equiv J v_{A}, K_{M} \equiv J v_{M}$, and $K_{\widetilde{J}} \equiv J v_{\widetilde{J}}$. We also use (42) and set $J=K$. This implies the following simplified production functions:

$$
\begin{aligned}
Y_{A} & =A_{A} K^{\phi \epsilon} K_{A}^{\phi} N_{A}^{\mu} L^{1-\phi-\mu} \\
Y_{M} & =A_{M} K^{\eta \epsilon} K_{M}^{\eta} N_{M}^{1-\eta} \\
v(\widetilde{J}) & =A_{\widetilde{J}} K^{\eta \epsilon} K_{\widetilde{J}}^{\eta} N_{\widetilde{J}}^{1-\eta}-F=v, \quad \forall \widetilde{J}
\end{aligned}
$$

57 The term $\left(1+\gamma_{N, t}\right) k_{t+1}$ in (4) results from the fact that capital will be divided among $\left(1+\gamma_{N, t}\right) N_{t}$ household members in the next period.

Springer 
where $N_{\widetilde{J}}=N_{\widetilde{J}}, \forall \widetilde{J}$ follows from symmetry in variety production and (29).

In the following steps we will derive the TFP paramater $A_{\widetilde{J}}$ as a function of $A_{M}$ such that, despite the fixed cost in capital variety production (55), this sector's output can be described by the manufacturing production function (54). First, recall from (39) that each capital variety producer's output is $F / \epsilon$. Second, we derive the labor and capital variety input needed to produce $F / \epsilon$ units of manufacturing output. Repeating steps (26) - (30) for the manufacturing sector and using symmetry of variety input prices yields

$$
\begin{aligned}
& N_{M}=\frac{1-\eta}{w} \frac{1}{A_{M} J^{\eta \epsilon}}\left(\frac{R_{K} p_{K}}{\eta}\right)^{\eta}\left(\frac{w}{1-\eta}\right)^{1-\eta} Y_{M} \\
& K_{M}=J v_{M}=\frac{\eta}{R_{K} p_{K}} \frac{1}{A_{M} J^{\eta \epsilon}}\left(\frac{R_{K} p_{K}}{\eta}\right)^{\eta}\left(\frac{w}{1-\eta}\right)^{1-\eta} Y_{M}
\end{aligned}
$$

Third, we suppose that we want to produce $F / \epsilon$ units of a new capital variety $\widetilde{J}-$ that is, using the capital variety technology (55) - with the labor and capital input given in (56) and (57) - i.e., the inputs needed when applying the manufacturing technology.

$$
F / \epsilon \stackrel{!}{=} v(\widetilde{J})=A_{\widetilde{J}} K^{\eta \epsilon}\left(\left.K_{M}\right|_{Y_{M}=F / \epsilon}\right)^{\eta}\left(\left.N_{M}\right|_{Y_{M}=F / \epsilon}\right)^{1-\eta}-F
$$

We now use the corresponding inputs, i.e., (56) and (57) evaluated at $Y_{M}=F / \epsilon$. This yields a constraint on the ratio of $A_{\widetilde{J}}$ and $A_{M}$ :

$$
A_{\widetilde{J}}=(1+\epsilon) A_{M}
$$

The price of capital varieties, as implied by (38), (32), and price symmetry, is then

$$
p_{\widetilde{J}}=(1+\epsilon) \frac{1}{A_{\widetilde{J}} K^{\eta \epsilon}}\left(\frac{R_{K} p_{K}}{\eta}\right)^{\eta}\left(\frac{w}{1-\eta}\right)^{1-\eta}=\frac{1}{A_{M} K^{\eta \epsilon}}\left(\frac{R_{K} p_{K}}{\eta}\right)^{\eta}\left(\frac{w}{1-\eta}\right)^{1-\eta}
$$

which is equal to marginal cost of manufacturing production, as can be verified by calculating total cost $C_{M}=w N_{M}+R_{K} K_{M}$ from (56) and (57) and deriving it with respect to $Y_{M}$. Due to perfect competition in final production, the price of output equals marginal cost, i.e., $p_{M}=M C_{M}$. Consequently, (60) implies $p_{\widetilde{J}}=p_{M}$, and, using (44) we obtain

$$
p_{K}=p_{M}
$$

By choosing $A_{\widetilde{J}}$ according to (59), each capital variety producer uses exactly the amounts of labor and capital inputs that a manufacturing firm would need in order to produce the same (fixed) output $F / \epsilon$ and charges the same price that a manufacturing producer would request. Intuitively, this result follows because the higher TFP in variety production exactly offsets the fixed cost $F$. We can thus incorporate the capital variety producing sector in the manufacturing sector. The simplification follows independent of our assumption $F=\epsilon$ that leads to (41). Also, increasing returns in variety production imply that the TFP advantage $A_{\widetilde{J}}>A_{M}$, necessary to compensate for $F$, decreases with output $v(\widetilde{J})$. It is therefore crucial that each capital variety firm produces a constant amount of output, as follows from (39), such that the necessary TFP difference is the same for all variety producers and constant over time.

In addition to consumers' demand, $Y_{M}^{d}$, manufacturing must also satisfy the demand for capital investment, as given by (43). ${ }^{58}$ Imposing market clearing, the total amount

58 Recall that the new capital produced in a given period is equal to $\int_{0}^{\widetilde{J}} v d \widetilde{J}=\widetilde{J}$ since $v=1, \forall \widetilde{J}$. 
of manufacturing supply, $Y_{M}$, must thus equal demand from households and capital investment $\left(I / p_{K}\right)$, where we can use $p_{K}=p_{M}$ :

$$
Y_{M}=Y_{M}^{d}+\frac{I}{p_{M}}
$$

The simplified model is thus equivalent to a two-sector model where capital investment goods are produced in the manufacturing sector.

\section{Appendix A.5 - Equilibrium conditions of the 2-sector model}

Having derived the two-sector version of the model in the previous section, we now present the corresponding equilibrium conditions. The FOC for agriculture and manufacturing profit maximization (19) - (23) can be easily simplified to their symmetric version by using $v_{i}(j)=v_{i}, \forall j$ and $i=A, M, \widetilde{J}$. The FOC's are the standard ones corresponding to profit maximization of (53) and (54). Factor payments to capital and labor are equal in both sectors, while land rents are determined in agriculture:

$$
\begin{aligned}
r_{L} & =(1-\phi-\mu) A_{A} K^{\phi \epsilon} K_{A}^{\phi} N_{A}^{\mu} L^{-\phi-\mu} \\
p_{K} R_{K} & =\phi A_{A} K^{\phi \epsilon} K_{A}^{\phi-1} N_{A}^{\mu} L^{1-\phi-\mu}=\eta p_{M} A_{M} K^{\eta \epsilon} K_{M}^{\eta-1} N_{M}^{1-\eta} \\
w & =\mu A_{A} K^{\phi \epsilon} K_{A}^{\phi} N_{A}^{\mu-1} L^{1-\phi-\mu}=(1-\eta) p_{M} A_{M} K^{\eta \epsilon} K_{M}^{\eta} N_{M}^{-\eta}
\end{aligned}
$$

Aggregate capital $K$ and population $N$ are given at the beginning of a period. In the following, we take per-capita expenditure $e$ as given and solve for the intratemporal equilibrium. From this solution we obtain $p_{M}$ and $R_{K}$, which we then use to solve the Euler Eq. (5). Total demand for agriculture products can be derived from (2): $Y_{A}^{d}=N c_{A}=N[\alpha e+(1-\alpha) \underline{c}]$. The remaining expenditure goes to manufacturing, which implies $Y_{M}^{d}=N c_{M}=N\left[(1-\alpha)(e-\underline{c}) / p_{M}\right]$. Total demand for manufacturing is given by (62). Markets clear for agriculture and manufacturing output:

$$
\begin{aligned}
N[\alpha e+(1-\alpha) \underline{c}] & =A_{A} K^{\phi \epsilon} K_{A}^{\phi} N_{A}^{\mu} L^{1-\phi-\mu}=Y_{A} \\
N \frac{(1-\alpha)}{p_{M}}(e-\underline{c})+\frac{I}{p_{M}} & =A_{M} K^{\eta \epsilon} K_{M}^{\eta} N_{M}^{1-\eta}=Y_{M}
\end{aligned}
$$

All land $L$ is used and factor markets clear:

$$
\begin{aligned}
& N_{A}+N_{M}=N \\
& K_{A}+K_{M}=K
\end{aligned}
$$

Finally, total nominal output, as given in Eq. (51), now simplifies to

$$
Y=Y_{A}+p_{M} Y_{M}
$$

This gives us a system with 13 unknowns: $Y, Y_{A}, Y_{M}, I, N_{A}, N_{M}, K_{A}, K_{M}, R_{K}, r_{L}$, $w, p_{M}, p_{K}$; and 13 equations: (61), (63), (68) - (70), and - each of the following counting twice - (64) - (67). Population growth is then derived from (12) and (13), where $c=c_{A}+c_{M}$ with $c_{A}=Y_{A} / N$ and $c_{M}=\left(p_{M} Y_{M}-I\right) /\left(p_{M} N\right)$. This system of equations characterizes the intratemporal equilibrium. We use the corresponding solution to derive per-capita expenditures $e$ from the Euler equation in the iterative process described in the next section. 
Appendix A.6 - Numerical simulations

In this section we outline the simulation of the equilibrium given in the previous section. Dividing (64) by (65) and using (68) and (69) to substitute $N_{M}$ and $K_{M}$ implies

$$
\frac{\phi}{\mu} \frac{N_{A}}{K_{A}}=\frac{\eta}{1-\eta} \frac{N-N_{A}}{K-K_{A}}
$$

This condition, together with (66), gives a system of two equations with two unknowns, $N_{A}$ and $K_{A}$, that we solve numerically for given $e$. Given $N_{A}$ and $K_{A}$, the remaining variables can be derived analytically.

To solve the Euler equation (5) we use policy function iteration where expenditure is a linear function of the (given) per-capita capital at the beginning of a period:

$$
e=\varphi k
$$

We discretize the shocks $\varepsilon$ to agricultural productivity using Gaussian quadrature with $Q$ nodes and corresponding weights $\omega_{q}$, defined by $\left\{\varepsilon_{q}, \omega_{q}\right\}_{q=1}^{Q}$. We use a projection method to solve for the coefficient $\varphi$, as described in the following steps:

1. Initialize by a guess $\varphi_{0}$ (a small positive number)

2. In iteration $l$, for $\varphi_{l}$, calculate $e$ according to (72)

3. For the given $e$, obtain $y=Y / N, \gamma_{N}$, and $p_{M}=p_{K}$ from the the intratemporal equilibrium and calculate next period's population $N^{\prime}=g N$

4. Evaluate the implied next period's p.c. capital, $k^{\prime}$, by

$$
k^{\prime}=\frac{1}{1+\gamma_{N}}\left[(1-\delta) k+\frac{y-e}{p_{K}}\right]
$$

and calculate $K^{\prime}=k^{\prime} N^{\prime}$.

5. Evaluate next period's consumption expenditure $e^{\prime}=\varphi k^{\prime}$. At all Gaussian quadrature nodes $q$, calculate $A_{A, q}^{\prime}=z_{q}^{\prime} \underline{A}_{A}^{\prime}$, where $\underline{A}_{A}^{\prime}=\left(1+\gamma_{A}\right) \underline{A}_{A}$ and $\ln z_{q}^{\prime}=$ $\theta \ln z+\varepsilon_{q}$

6. For the given $N^{\prime}, K^{\prime}, e^{\prime}$, and $A_{A, q}^{\prime}$ obtain $y_{q}^{\prime}=Y_{q}^{\prime} / N^{\prime}, g_{q}^{\prime}$, and $p_{M, q}^{\prime}=p_{K, q}^{\prime}$ from the intratemporal equilibrium for $q=1, \ldots, Q$

7. Evaluate expenditure implied by the Euler equation as

$$
\widetilde{e}=\left[\beta \sum_{q=1}^{Q} \omega_{q}\left(\frac{p_{K, q}^{\prime}}{p_{K}}\right)\left(\frac{p_{M, q}^{\prime}}{p_{M}}\right)^{(1-\alpha)(\psi-1)}\left(\frac{1}{e_{q}^{\prime}-\underline{c}}\right)^{\psi}\left(R_{K, q}^{\prime}+1-\delta\right)\right]^{-\frac{1}{\psi}}+\underline{c}
$$

8. Calculate $\widetilde{\varphi}=\tilde{e} / k$

9. If $\|\varphi-\tilde{\varphi}\|<10^{-9}$, stop the iteration and accept $\varphi$ as a solution. Otherwise use a Broyden solver to update $\varphi_{l+1}$ and go to step 2 . Repeat until convergence.

Appendix A.7 - Calibration of the British birth function

In this section we describe the calibration of the net birth rate function $g_{b}(c)$ based on British historical data, as shown in Fig. 8. Crucially for our purposes, English birth rates responded positively to higher wages, as demonstrated by Wrigley and Schofield (1981), and Wrigley et al. (1997). To derive the function's exact shape, we use an exercise similar in spirit to Hansen and Prescott (2002). We employ a spline 


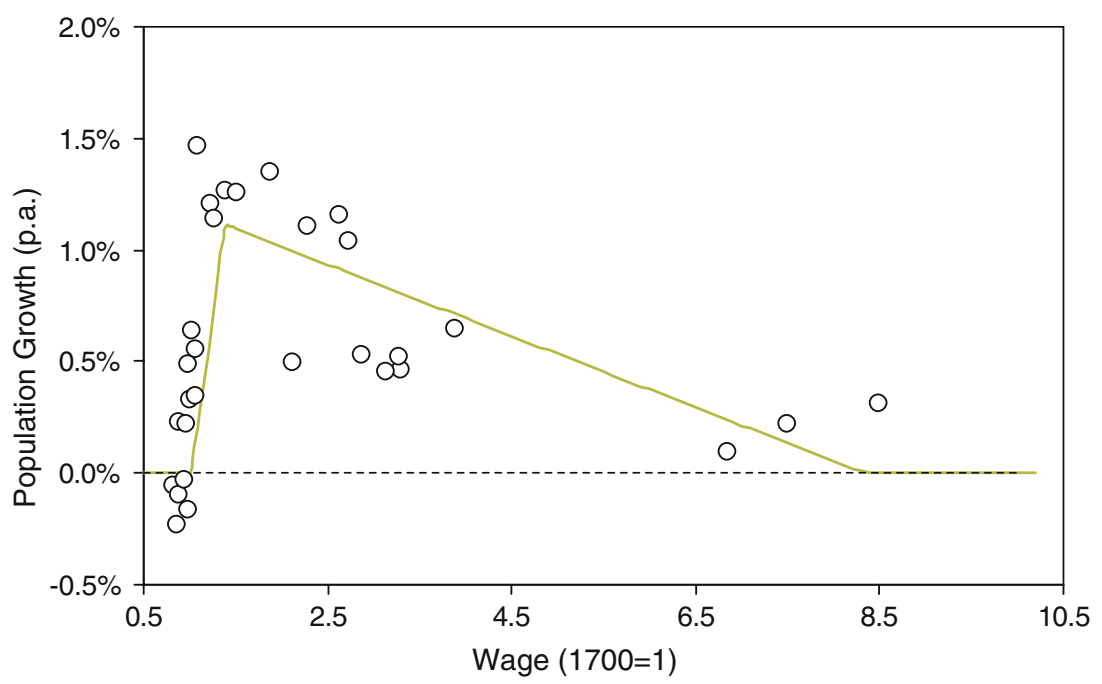

Fig. 8 Population growth and wage in England. Sources: Population: Wrigley and Schofield (1981) for 1541-1871; (1971) for 1881-1961. Real wages: Clark (2005)

regression, defining $x=w / w_{0}$, where $w_{0}$ represents the wage in 1700 . Population growth, is $y_{p}\left(x_{t}\right)=N_{t+1} / N_{t}-1$. Let $x_{\text {peak }}$ denote the cutoff-point at which the slope changes its sign from positive to negative. We then define a dummy $d=1$, whenever $x \leq x_{\text {peak }}$ and zero, else. Population growth in 1700 was close to zero; we thus impose $y_{p}\left(w_{0} / w_{0}\right)=y_{p}(1)=0$. The spline regression is

$$
y_{p}(x)=\beta_{1} \underbrace{\left[(x-1) d+\left(x_{\text {peak }}-1\right)(1-d)\right]}_{x_{1}}+\beta_{2} \underbrace{\left(x-x_{\text {peak }}\right)(1-d)}_{x_{2}}+u
$$

where $u$ is an error term. When running this regression (without constant) we choose the cutoff-point $x_{\text {peak }}$ to maximize $R^{2}$, and obtain $\widehat{\beta}_{1}=0.0277(t=8.03)$ and $\widehat{\beta}_{2}=$ $-0.0016(t=-3.39) ; x_{\text {peak }}=1.4$; the adjusted $R^{2}$ is 0.70 . As in Hansen and Prescott (2002), we impose that demographic growth rates cannot be negative because incomes are too high. For very low income, the net birth rate is zero and population diminishes due to starvation as described in Section 3.4.4. The $g_{b}(\cdot)$ function for England is then defined as

$$
g_{b}(x)=\left\{\begin{array}{l}
\max \left\{\widehat{\beta}_{1}(x-1), 0\right\}+1, \text { if } x \leq x_{\text {peak }} \\
\max \left\{\widehat{\beta}_{1}\left(x_{\text {peak }}-1\right)+\widehat{\beta}_{2}\left(x-x_{\text {peak }}\right), 0\right\}+1, \text { else }
\end{array}\right.
$$

\section{References}

Acemolgu, D., \& Zilibotti, F. (1997). Was prometheus unbound by chance? Risk, Diversification, and Growth. Journal of Political Economy, 105(4), 709-751.

Allen, R. C. (1992), Enclosure and the Yeoman/the agricultural development of the South Midlands. Oxford: OUP, pp. 1450-1850.

Allen, R. C. (2005a). Real wages in Europe and Asia: A first look at the long-term patterns. In R. C. Allen, T. Bengtsson, \& M. Dribe (eds), Living standards in the past. Oxford: OUP.

Allen, R. C. (2005b). Capital Accumulation, Technological Change, and the Distribution of Income during the British Industrial Revolution. Nuffield College working paper. 
Allen, R. C. (2006). Agricultural Productivity and Rural Incomes in England and the Yangtze Delta, c. 1620 - c. 1820 . Nuffield College working paper.

Allen, R. C., Bassino, J.-P., Ma, D., Moll-Murata, C., \& van Zanden, J. L. (2005). Wages, Prices, and Living Standards in China, Japan, and Europe, 1738-1925. Working paper.

Antras, P. \& Voth, H.-J. (2003). Factor prices and productivity growth during the British industrial revolution. Explorations in Economic History, 38, 52-77.

Ashton, T. S. (1964). The Industrial Revolution, 1760-1830. Oxford: OUP.

Boyer, G. (1990). An economic history of the English poor law, 1750-1850. Cambridge: CUP.

Broadberry, S. \& Gupta, B. (2005a). The Early Modern Great Divergence: Wages, Prices and Economic Development in Europe and Asia, 1500-1800. Warwick working paper.

Broadberry, S. \& Gupta, B. (2005b). Cotton Textiles and the Great Divergence: Lancashire, India and Shifting Competitive Advantage, 1600-1850. Warwick working paper.

Braudel, F. (1973). Capitalism and Material Life, 1400-1800. New York, Harper and Row.

Cervellati, M. \& Sunde, U. (2005). Human capital formation, life expectancy, and the process of development. American Economic Review, 95(5), 1653-1672.

Chesnais, F. (1992). The demographic transition. Oxford: OUP.

CIA (2005). CIA fact book 2005: http://www.cia.gov/cia/publications/factbook/

Clark, G. (2003a). The Great Escape: The Industrial Revolution in Theory and in History. Unpublished manuscript, UC Davis.

Clark, G. (2003b). Agricultural productivity, prices and wages. In: J. Mokyr (ed.), Encylopedia of Economic History, Vol. 1. Oxford: Oxford University Press, pp. 92-96.

Clark, G. (2005). The Condition of the working-class in England, 1209-2004. Journal of Political Economy, 113(6), 1307-1340.

Cole, W. A. (1973). Eighteenth-century economic growth revisited. Explorations in Economic History, 10, 327-348.

Crafts, N. F. R. (1977). Industrial revolution in England and France: Some thoughts on the question, 'Why Was England First?'. Economic History Review, Second Series, 30(3), 429-441.

Crafts, N. F. R. (1985). British economic growth during the industrial revolution. Oxford: OUP.

Crafts, N. F. R. (1995). Exogenous or endogenous growth? The industrial revolution reconsidered. Journal of Economic History, 55(4), 745-772.

Crafts, N. F. R., \& Harley, K. (1992). Output growth and the British industrial revolution: A restatement of the Crafts-Harley view. Economic History Review, 45, 703-730.

Crafts, N. F. R., \& Harley, K. (2000). Simulating the two views of the industrial revolution. Journal of Economic History, 60, 819-841.

Diamond, J. (2004). Collapse: How societies choose to fail or succeed. New York: Viking.

Feinstein, C. (1981). Capital accumulation and the industrial revolution. In: R. Floud \& D. McCloskey (eds), The Economic history of Britain since 1700, Vol. I. Cambridge: CUP.

Fogel, R. (1994). Economic growth, population theory, and physiology: The bearing of long-term processes on the making of economic policy. American Economic Review, 84(3), 369-395.

Galor, O. (2005). From stagnation to growth: Unified growth theory. In: P. Aghion \& S. Durlauf (eds), Handbook of economic growth, Vol. 1A. Amsterdam: North-Holland.

Galor, O., \& Moav, O. (2002). Natural selection and the origin of economic growth. Quarterly Journal of Economics, 117(4), 1133-1191.

Galor, O., \& Moav, O. (2004). From physical to human capital accumulation: Inequality and the process of development. Review of Economic Studies, 71, 1001-1026.

Galor, O., \& Mountford, A. (2003). Trade, Demographic Transition, and the Great Divergence: Why are a Third of People Indian or Chinese? Hebrew University Working Paper.

Galor, O., \& Weil, D. (2000). Population, technology and growth: From the malthusian regime to the demographic transition and beyond. American Economic Review, 90, 806-828.

Gilboy, E. (1932). Demand as a factor in the industrial revolution. reprinted in: A. H. Cole (ed), Facts and factors in economic history. Cambridge, MA: Harvard University Press.

Goldstone, J. (2002). Efflorescences and economic growth in world history. Rethinking the "Rise of the West" and the industrial revolution. Journal of World History, 13(2), 323-389.

Hajnal, J. (1965). European marriage in perspective. In: D. V. Glass, \& D. E. C. Eversley, (eds), Population in history. London: Arnold.

Hansen, G. D., \& Prescott, E. (2002). Malthus to solow. American Economic Review, 92(4), 1205-1217.

Horrell, S. (1996). Home demand and British industrialization. Journal of Economic History, 56(3), $561-604$.

Jones, C. (2001). Was an industrial revolution inevitable? Economic growth over the very long run. Advances in Macroeconomics, 1(2). 
King, P. (1997). Pauper inventories and the material lives of the poor in the eighteenth and early nineteenth centuries. In: T. Hitchcock, P. King, \& P. Sharpe (eds), Chronicling poverty: The voices and strategies of the english poor. Basingstoke: Houndsmills.

Kögel, T., \& Prskawetz, A. (2001), Agricultural procutivity growth and escape from the malthusian trap. Journal of Economic Growth, 6, 337-357.

Labrousse, E., Romano, R., \& Dreyfus, F.-G. (1970). Le Prix Du Froment en France 1726-1913. Paris: SEVPEN.

Lagerlöf, N.-P. (2003). From malthus to modern growth: Can epedemics explain the three regimes. International Economic Review, 44(2), 755-777.

Lagerlöf, N.-P. (2006). The Galor-Weil model revisited: A quantitative exploration. Journal of Economic Dynamics, 9(1), 116-142.

Landes, D. (1999). The wealth and poverty of nations: Why some are so rich and some so poor. Harvard: Harvard University Press.

Lindert, P. H. (2000). When did inequality rise in Britain and America? Journal of Income Distribution, $9(1), 11-25$.

Lindert, P. H., \& Williamson, J. G. (1982). Revising england's social tables, 1688-1812. Explorations in Economic History, 19(4), 385-408.

Maddison, A. (2003). The world economy: Historical statistics. Paris, France: Development Centre of the OECD.

Matsuyama, K. (1991). Increasing returns, industrialization, and indeterminacy of equilibrium. Quarterly Journal of Economics, 106(2), 617-650.

Matsuyama, K. (2002). The rise of mass consumption societies. Journal of Political Economy, 110(5), $1035-1070$.

McCloskey, D. N., \& John, N. (1984). Corn at interest: The extent and cost of grain storage in medieval england. American Economic Review, 74(1), 174-187.

Mitchell, B. R., \& Jones, H. G. (1971). Second abstract of British historical statistics. Cambridge: CUP.

Mokyr, J. (1977). Demand vs. supply in the industrial revolution. Journal of Economic History, 37(4), 981-1008.

Mokyr, J. (1990). The lever of riches: Technological creativity and economic progress. New York: Oxford University Press.

Mokyr, J. (1999). Editor's introduction. The new economic history and the industrial revolution. In: J. Mokyr (ed), The British industrial revolution: An economic perspective. Boulder, CO: Westview.

Mokyr, J. (2002). Why was the industrial revolution a European phenomenon? Supreme Court Economic Review, 9.

Mokyr, J., \& Voth, H.-J. (2008). Understanding Growth in Europe, 1700-1870 - First Industrializations, Unified Growth Theory, and Beyond. In: S. Broadberry, Kevin O'Rourke, Cambridge economic history of europe, Vol. I, Cambridge, forthcoming.

Mosk, C. (1976). Fecundity, infanticide, and food consumption in Japan. Explorations in Economic History, 15(3), 269-289.

Murphy, K. M., Shleifer, A., \& Vishny, R. W. (1989a). Income distribution, market size, and industrialization. Quarterly Journal of Economics, 104(3), 537-564.

Murphy, K. M., Shleifer, A., \& Vishny, R. (1989b). Industrialization and the big push. Journal of Political Economy, 97(5), 1003-1026.

North, D. C., \& Thomas, R. P. (1973). The rise of the western world: A new economic history. Cambridge, Cambridge University Press.

Pomeranz, K. (2000). The great divergence: China, Europe, and the making of the modern world economy. Princeton, NJ: Princeton University Press.

Romer, P. M. (1990). Endogenous technological change. Journal of Political Economy, 98(5), 71-102.

Rozman, G. (1973). Urban Networks in Ch'ing China and Tokugawa Japan. Princeton, NJ: Princeton University Press.

Stokey, N. (2001). A Quantitative model of the British industrial revolution, 1780-1850. CarnegieRochester Conference Series on Public Policy, 55, 55-109.

Strulik, H. (2006), Patterns of Demographic Development and Structural Change. University of Copenhagen working paper.

Temin, P., \& Voth, H.-J. (2005). Credit rationing and crowding out during the industrial revolution: Evidence from hoare's Bank 1702-1862. Explorations in Economic History, 42(3), 325-348.

Voth, H.-J. (2003). Living standards during the industrial revolution: An economist's guide. American Economic Review, 93(2), 221-226.

de Vries, J. (1984). European urbanization 1500-1800. London: Methuen. 
Williamson, J. G. (1984). Why was British growth so slow during the Industrial Revolution? Journal of Economic History, 44(3), 687-712.

Wrigley, E. A. (1983). The growth of population in eighteenth-century England: A conundrum resolved. Past and Present, 98, 121-150.

Wrigley, E. A. (1988). Continuity, chance and change: The character of the industrial revolution in England. Cambridge: Cambridge University Press.

Wrigley, E. A., Davies, R. S., Oeppen, J. \& Schofield, R. (1997). English population history from family reconstitution 1580-1837. Cambridge: CUP.

Wrigley, E. A., \& Schofield, R. (1981). The population history of England, 1541-1871: A reconstruction. Cambridge, MA, Harvard University Press.

Zweimüller, J. (2000). Schumpeterian entrepreneurs meet Engel's Law: The impact of inequality on innovation-driven growth. Journal of Economic Growth, 5(2), 185-206. 